Review Article

\title{
Current Concepts and Future Directions for the Assessment of Autoantibodies to Cellular Antigens Referred to as Anti-Nuclear Antibodies
}

\author{
Michael Mahler, ${ }^{1}$ Pier-Luigi Meroni, ${ }^{2}$ Xavier Bossuyt, ${ }^{3}$ and Marvin J. Fritzler ${ }^{4}$ \\ ${ }^{1}$ INOVA Diagnostics, Inc., 9900 Old Grove Road, San Diego, CA 92131-1638, USA \\ ${ }^{2}$ Rheumatology \& Experimental Laboratory of Immuno-rheumatology, University of Milan, Istituto Auxologico Italiano, \\ Via G. Zucchi 18, 20095 Cusano Milanino, Milan, Italy \\ ${ }^{3}$ Department of Microbiology and Immunology, Laboratory Medicine, University Hospitals Leuven, KU Leuven, Belgium \\ ${ }^{4}$ Faculty of Medicine, University of Calgary, Calgary, Alberta, Canada T2N 4N1
}

Correspondence should be addressed to Michael Mahler; mmahler@inovadx.com

Received 13 December 2013; Accepted 27 January 2014; Published 27 April 2014

Academic Editor: Ghislain Opdenakker

Copyright (C) 2014 Michael Mahler et al. This is an open access article distributed under the Creative Commons Attribution License, which permits unrestricted use, distribution, and reproduction in any medium, provided the original work is properly cited.

\begin{abstract}
The detection of autoantibodies that target intracellular antigens, commonly termed anti-nuclear antibodies (ANA), is a serological hallmark in the diagnosis of systemic autoimmune rheumatic diseases (SARD). Different methods are available for detection of ANA and all bearing their own advantages and limitations. Most laboratories use the indirect immunofluorescence (IIF) assay based on HEp-2 cell substrates. Due to the subjectivity of this diagnostic platform, automated digital reading systems have been developed during the last decade. In addition, solid phase immunoassays using well characterized antigens have gained widespread adoption in high throughput laboratories due to their ease of use and open automation. Despite all the advances in the field of ANA detection and its contribution to the diagnosis of SARD, significant challenges persist. This review provides a comprehensive overview of the current status on ANA testing including automated IIF reading systems and solid phase assays and suggests an approach to interpretation of results and discusses meeting the problems of assay standardization and other persistent challenges.
\end{abstract}

\section{Introduction}

In 1950, Coons and Kaplan described the improvement of an immunofluorescence method for the detection of antigens in tissue cells [1]. Eight years later, Friou et al. first described an indirect immunofluorescence (IIF) assay for the detection of anti-nuclear antibodies (ANA) [2,3]. Along with the earlier discovery of the lupus erythematosus (LE) cell and the development of the LE cell test $[4,5]$, this ushered in a long and productive age of ANA testing. The ANA IIF test initially relied on rodent tissue substrates but contemporary tests use HEp-2 cells, a cell line established in 1952 by Moore and her colleagues from tumors that had been produced in weanling rats exposed to irradiation and corticosteroids injected with epidermoid carcinoma tissue from the larynx of a 56-year-old male [6]. In the following decades, ANA tests using HEp-2 cells revolutionized the diagnosis of ANA associated rheumatic diseases (AARD) including systemic lupus erythematosus (SLE), systemic sclerosis (SSc), Sjögren's syndrome ( $\mathrm{SjS})$, mixed connective tissue disease (MCTD), and idiopathic inflammatory myopathies (IIM) $[7,8]$.

The IIF assay on HEp-2 cells has been replaced in many laboratories since the development of ANA screening assays based on ELISA and automated, high throughput multiplex assays using addressable laser bead and other array technologies for the detection of specific ANA [9, 10]. Due to a significant prevalence of "false negative" ANA results on these newer platforms and an insufficient communication between laboratorians and clinicians, there have been growing concerns about unilateral adoption of these newer screening and high throughput assays [11]. Questions about which method should be used and the lack of standardization of the novel test algorithms led the American College of Rheumatology (ACR) to form 
TABLE 1: Statistical terms relevant for ANA testing.

\begin{tabular}{|c|c|c|}
\hline Statistical measure & General explanation & Implication for ANA \\
\hline Sensitivity & $\begin{array}{l}\text { Statistical measure of how accurately a test } \\
\text { correctly identifies diseased individuals }\end{array}$ & $\begin{array}{l}\text { ANA is used as screening test. High sensitivity is } \\
\text { important. The sensitivity for different AARD } \\
\text { varies (i.e., higher in systemic lupus } \\
\text { erythematosus versus myositis) }\end{array}$ \\
\hline Specificity & $\begin{array}{l}\text { Statistical measure of how well a test correctly } \\
\text { identifies absence of the disease in question }\end{array}$ & $\begin{array}{l}\text { Importance of specificity depends on pretest } \\
\text { probability. In settings with low pretest } \\
\text { probability, high specificity is required. }\end{array}$ \\
\hline Diagnostic efficiency & Combination of sensitivity and specificity & Not commonly used \\
\hline False negative (clinically) & Negative test result of a diseased individual & $\begin{array}{l}\text { ANA is used as screening test. False negative } \\
\text { results are undesirable. However, in all AARD, } \\
\text { patients without a positive ANA test exist. } \\
\text { Therefore, a negative result should never be used } \\
\text { to rule out AARD. }\end{array}$ \\
\hline False positive (clinically) & $\begin{array}{l}\text { Positive test result of an individual without the } \\
\text { disease in question }\end{array}$ & $\begin{array}{l}\text { In case of low pretest probability, false positive } \\
\text { results significantly impact the posttest probability }\end{array}$ \\
\hline False negative (analytically) & $\begin{array}{l}\text { Negative test result in the presence of the } \\
\text { respective analyte }\end{array}$ & See negative positive (clinically) \\
\hline False positive (analytically) & $\begin{array}{l}\text { Positive test result in the absence of the } \\
\text { respective analyte }\end{array}$ & See false positive (clinically) \\
\hline Positive predictive value & $\begin{array}{l}\text { Ratio of true positive to combined true and } \\
\text { false positives. }\end{array}$ & Depends on the prevalence (pretest probability) \\
\hline Negative predictive value & $\begin{array}{l}\text { Ratio of true negatives to combined true and } \\
\text { false negatives. }\end{array}$ & Depends on the prevalence (pretest probability) \\
\hline Positive likelihood ratio & $\begin{array}{l}\text { The probability of a positive test results in } \\
\text { patients with the disease divided by the } \\
\text { probability of a positive test result in } \\
\text { individuals without the disease. Independent } \\
\text { from prevalence. }\end{array}$ & $\begin{array}{l}{ }^{\#} \text { Important information for clinicians. Should be } \\
\text { included in the laboratory report together with an } \\
\text { explanation of its significance in the context of the } \\
\text { test result. }\end{array}$ \\
\hline Negative likelihood ratio & $\begin{array}{l}\text { The probability of a negative test result in } \\
\text { patients with the disease divided by the } \\
\text { probability of a negative test result in } \\
\text { individuals without the disease. Independent } \\
\text { from prevalence. }\end{array}$ & $\begin{array}{l}{ }^{*} \text { Important information for clinicians. Should be } \\
\text { included in the laboratory report together with an } \\
\text { explanation of its significance in the context of the } \\
\text { test result. }\end{array}$ \\
\hline
\end{tabular}

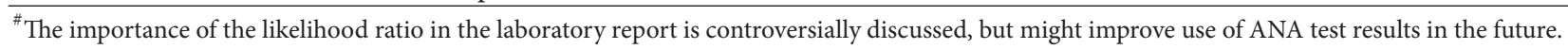

a task force who recommended the use of the conventional IIF HEp-2 platform for ANA detection [12]. This recommendation was, in part, based on evidence that the HEp2 cell substrates are essentially an "array" presenting $>100$ autoantibody targets whereas most high throughput screening arrays are much more limited in autoantibody target composition. This has prompted a reevaluation of the ANA IIF method which was reflected by entire sessions dedicated to HEp-2 ANA testing at international clinical and scientific meetings.

In recent years, the first digital imaging systems for ANA IIF have been developed which eliminate some major drawbacks of the method, namely, the subjectivity of observers reading the slides and the lack of an automated procedure [15-17]. Nevertheless, several drawbacks of the HEp2 IIF methods persist and other technologies for ANA detection continue to emerge and evolve. In this review, novel insights and updates on ANA detection are presented and the pros and cons of different methods are discussed.

\section{Statistical Considerations}

2.1. Sensitivity and Specificity. For diagnostic applications, it is important to differentiate between analytical sensitivity/specificity and clinical (diagnostic) sensitivity/specificity. Therefore, the terms clinical sensitivity and specificity, false negative, false positive, and predictive values are described in Table 1. In addition, it is widely known and extensively documented that certain autoantibodies can precede the diagnosis or full clinical expression of an underlying disease for many years and thus false positive results at a given point in time might, over a subsequent time period, become a true positive $[18,19]$. Consequently, the term "false positive" for autoantibodies needs to be used carefully.

2.2. ROC Analysis and Cut-Off Selection. The receiver operating characteristic (ROC) analysis has a broad range of applications and was first used for military purposes during World War II [20]. In medicine, ROC analysis has been 


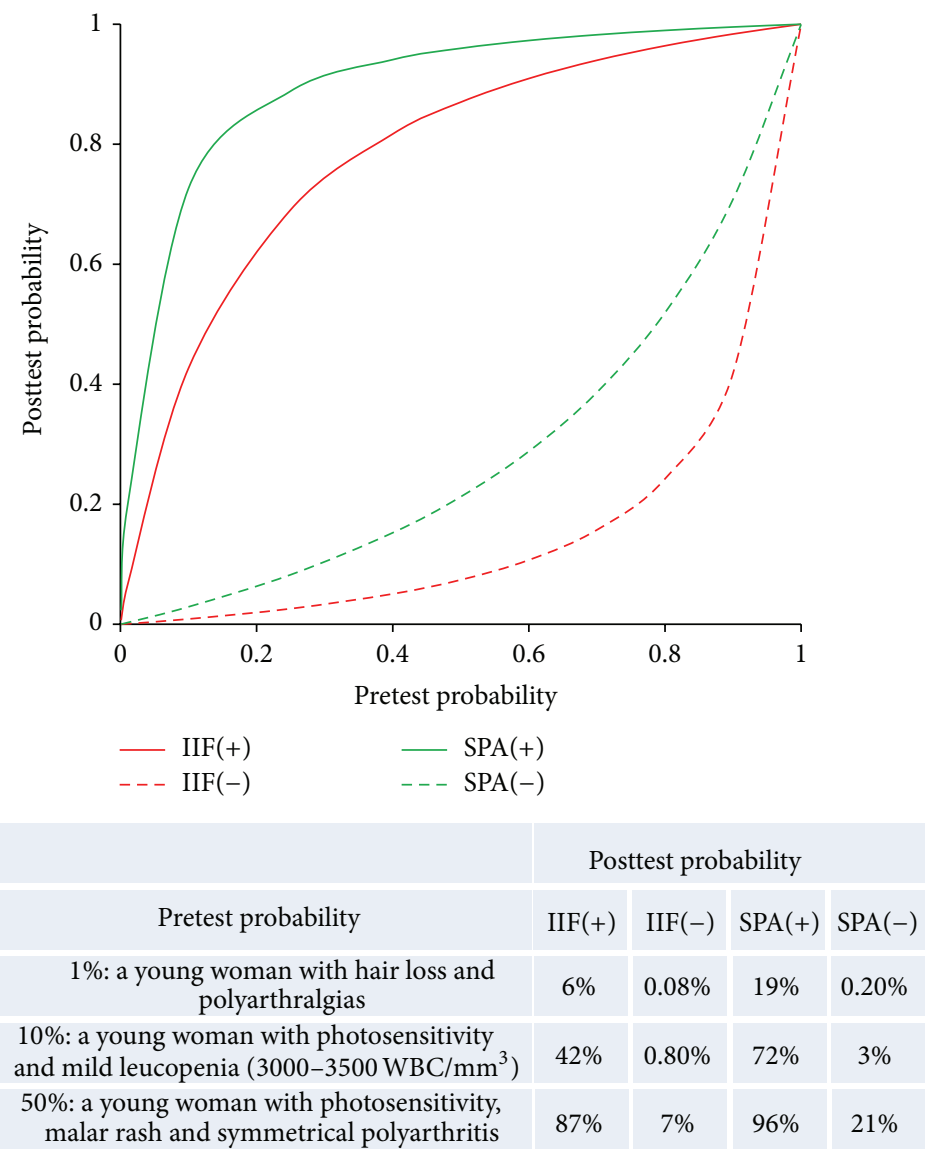

FIGURE 1: Illustration of pretest and posttest probability. Posttest probability (predictive value) for systemic lupus erythematosus as a function of pretest probability and as a function of indirect immunofluorescence (IIF) and solid phase assay (SPA) (EliA CTD screen, Thermo Fisher) test result. Values for likelihood ratios are from Bossuyt and Fieuws [31], WBC = white blood cell.

extensively used for diagnostic testing to evaluate the effectiveness of a novel diagnostic method as compared to an already established one or so called "gold standard" method. Several statistical methods can be applied using the ROC analysis including the most commonly used area under the curve (AUC). The AUC is equivalent to the Mann-Whitney $U$, which tests for the median difference between scores obtained in the two continuous data sets. However, any attempt to summarize the ROC curve into a single number fails as information about the pattern of tradeoffs of the particular discriminator algorithm is not expressed.

The manner by which immunoassay cut-offs are established varies significantly among researchers and scientists in diagnostic companies. A common approach to define the cutoff value for certain assays is to test specimens from patients with the respective disease and compare them to a broad range of controls including related and unrelated diseases as well as age and gender matched (apparently) healthy individuals. The mean value plus 3 -fold standard deviation, the $95 \%$ or the $99 \%$ percentile, of the controls are then often used to define the cut-off value. Another popular approach for definition of the cut-off value makes use of ROC analysis. Despite broad application, most references do not specify how to use the ROC analysis to define the cut-off value [21]. In the majority of cases, a visual approach is used to identify an appropriate point on the ROC curve which provides a good combination of sensitivity and specificity. Following this, it is important that the cohort used to define the cut-off (training set) is large enough to achieve statistical power and that the cut-off is validated using an independent cohort of patients (validation set).

The method used for cut-off definition strongly depends on the assay and how it is intended to be used in a routine setting. For a screening assay, a high degree of sensitivity is mandatory to ensure that the number of patients that are missed by the assay is kept as low as possible. In contrast, confirmation tests need high specificity. In general, low cutoff values increase the sensitivity at the expense of decreasing specificity and vice versa when a higher cut-off is defined $[9,10]$.

The interpretation of the ANA test results depends on the pretest probability of having the disease or whether fulminant disease is present. In a setting of high index of suspicion, even low titers of ANA-IIF can be interpreted as significant [22]. In 1997 it was suggested by Tan and colleagues [23] that the test should be performed and reported at two dilutions, $1: 40$ and $1: 160$, in order to preserve the appropriate sensitivity and specificity. A more recent study recommended using a more 
economical single screening dilution of $1: 160$ [24] which was confirmed by a recommendation paper that used a Delphi approach for assessment of autoantibodies to intracellular antigens [21]. ANA-IIF testing on HEp-2 cells is currently widely accepted as the procedure of choice for the detection of ANA but not as a corollary of disease activity or relapse [21].

2.3. Likelihood Ratio. In clinical practice, an important and relevant question is "What is the probability of a patient having a particular disease when the laboratory test is positive or not having the disease when the laboratory test is negative?" [25]. Clinicians and laboratory professionals have difficulties in estimating the posttest probability for a disease based on sensitivity and specificity (2). Likelihood ratio (LR) is an alternative, and probably more easily understood, way to convey diagnostic accuracy data in a clinical setting [26]. The LR for a disease is the probability of the test result in patients with the disease divided by the probability of the same test result in individuals without the disease. The posttest probability for disease associated with a particular test result can be estimated based on the pretest probability and the LR for that particular test result $[25,27]$.

Traditionally, a single cut-off is used for the interpretation of a laboratory test and all values above or below the cutoff value are given the same interpretation (positive or negative, resp.). For many AARD, the likelihood for disease increases with increasing antibody concentration [28-30]. This information is lacking when a single cut-off is used. LR can be assigned to a particular test result or to a test result interval (e.g., the antibody titer of ANA). It has been shown that the LR for an AARD increases with increasing antibody levels [28]. Knowledge of test result (interval) specific LR improves the clinical interpretation of a particular test result compared to knowledge related to a single cut-off value.

The LR gives an estimation of whether there will be a significant change in pretest to posttest probability of disease given the test result [25]. A LR of 1 implies that there will be no difference between pretest and posttest probability [25]. LRs $>10$ or $<0.1$ indicate large, often clinically significant, differences. LRs between 5 and 10 and between 0.1 and 0.2 indicate modest clinical differences [25].

The LR for SLE for ANA by IIF has been estimated to be 7 for a positive test result and 0.03 for a negative test result, whereas the LR for SLE based on solid phase assays (SPA) [in this case: Fluoro enzyme immunoassay (FEIA), EliA CTD screen] has been estimated to be 24 for a positive test result and 0.27 for a negative test result [31]. Using LRs, one can calculate the posttest probability for any given pretest probability [25]. Figure 1 illustrates a graphical representation of the posttest probability (predictive value) for SLE as a function of the pretest probability for IIF as well as for SPA. Such graphical representation has been shown to be a convenient way to convey diagnostic information [26].

To illustrate the impact of pretest probability and assay performance on the posttest probability clinical examples are provided (unpublished data, based on expert experience of Pier-Luigi Meroni).
TABLE 2: Anti-nuclear antibodies (ANA) in different ANA associated autoimmune rheumatic diseases and healthy individuals.

\begin{tabular}{|c|c|c|c|c|c|c|}
\hline \multirow{2}{*}{ Antibody } & \multicolumn{5}{|c|}{ AARD } & \multirow[b]{2}{*}{ HI } \\
\hline & SLE & $\mathrm{SSc}$ & SjS & IM & MCTD & \\
\hline dsDNA & $40-70 \%$ & $<3 \%$ & $<3 \%$ & $3 \%$ & -370 & $<3 \%$ \\
\hline Chroma & $40-70 \%$ & $<3 \%$ & $<3 \%$ & $<3 \%$ & $5-18 \%$ & $<3 \%$ \\
\hline RNP & $10-40 \%$ & $5-15 \%$ & $<3 \%$ & $5-15 \%$ & $100 \%^{5}$ & $<3 \%$ \\
\hline$m$ & $5-20 \%$ & $<2 \%$ & $<1 \%$ & $<1 \%$ & $<2 \%^{2}$ & $<1 \%$ \\
\hline & $40-7$ & $3-10 \%$ & $60-90 \%$ & $<3 \%$ & $<30$ & $<3 \%$ \\
\hline 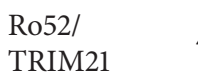 & $40-70 \%$ & $15-30 \%$ & $70-90 \%$ & $25-50 \%$ & $<3 \%$ & $<3 \%$ \\
\hline D/I & $15-30 \%$ & $1-5 \%$ & $60-80 \%$ & $5-15 \%$ & $<3 \%$ & $<3 \%$ \\
\hline Scl-7 & $0-5 \%$ & $20-40 \%^{4}$ & $<3 \%$ & $<3 \%$ & $<3 \%$ & $<1 \%$ \\
\hline Jo-1 & $1-3 \%$ & $1-3 \%$ & $<2 \%$ & $15-30 \%$ & $<2 \%$ & $<1 \%$ \\
\hline Centro & $2-5 \%$ & $20-40 \%^{4}$ & $5-10 \%$ & $1-3 \%$ & $2-5 \%$ & $<3 \%$ \\
\hline RNA Pol III & $<1 \%$ & $5-25 \%{ }^{4}$ & $<1 \%$ & $<1 \%$ & $<1 \%$ & $<1 \%$ \\
\hline mal P & $10-30 \%$ & $<2 \%$ & $<2 \%$ & $<2 \%$ & $<2 \%$ & $<1 \%$ \\
\hline & $1-3 \%$ & $5-10 \%$ & $<2 \%$ & $5-10 \%$ & $<2 \%$ & $<3 \%$ \\
\hline $\mathrm{Mi}-2$ & $<1 \%$ & $3-8 \%$ & $<1 \%$ & $5-15 \%{ }^{1}$ & $<1 \%$ & $<3 \%$ \\
\hline $\mathrm{Ku}$ & $5-20 \%$ & $3-8 \%$ & $<3 \%$ & $3-10 \%^{3}$ & $<3 \%$ & $<3 \%$ \\
\hline & $<5 \%$ & $<1 \%$ & $<1 \%$ & $<1 \%$ & $<1 \%$ & $<3 \%$ \\
\hline Th/To & $<1 \%$ & $3-10 \%$ & $<1 \%$ & $<1 \%$ & $<1 \%$ & $<1 \%$ \\
\hline
\end{tabular}

${ }^{1}$ Rare in PM, higher prevalence in DM; mild form of disease; early during development.

${ }^{2}$ Prevalence depends if antigen contains $\mathrm{SmBB}^{\prime}$ (cross-reactive with RNP). ${ }^{3}$ Very high titer in PM.

${ }^{4}$ Anti-Scl-70, anti-centromere, anti-RNA Pol III antibodies tend to be mutually exclusive.

${ }^{5}$ Part of the classification criteria, therefore should be $100 \%$; however, depending on assay used, some patients might be negative.

Note: Prevalence values were established based on literature and consensus of authors.

Abbreviations: DM: dermatomyositis; IIM: idiopathic inflammatory myopathy (polymyositis/dermatomyositis); MCTD: mixed connective tissue disease; PCNA: proliferating cell nuclear antigen; PM: polymyositis; RA: rheumatoid arthritis; RNA pol III: RNA polymerase III; RNP: ribonucleoprotein; Sm: Smith antigens (U2-U6 RNP); SjS: Sjögren's syndrome; SLE: systemic lupus erythematosus; SPA: Solid phase assay; SSc: systemic sclerosis; TRIM: tripartite motif.

For example, a young woman with hair loss and polyarthralgias, which are very nonspecific signs of SLE, is estimated to have a pretest probability for SLE of $1 \%$. If ANA by IIF turns out to be positive in this patient the probability for SLE increases from $1 \%$ to $6 \%$, which is still low. If the SPA CTD screen reveals an autoantibody directed to a specific nuclear antigen (ENA or dsDNA), then the probability for SLE is higher (19\%). A second example is a young woman who presents to her physician with photosensitivity and mild leucopenia $\left(3000-3500 \mathrm{WBC} / \mathrm{mm}^{3}\right)$. Based on this clinical presentation, the probability for SLE is estimated to be $10 \%$. A positive ANA by IIF increases the probability for SLE to $42 \%$, whereas a positive SPA CTD screen increases the probability for SLE to $72 \%$, which makes the diagnosis for SLE likely. However, a woman positive for anti-SSA/Ro could display the same clinical manifestations not necessarily having SLE (sometimes the sicca syndrome is clinically silent at 


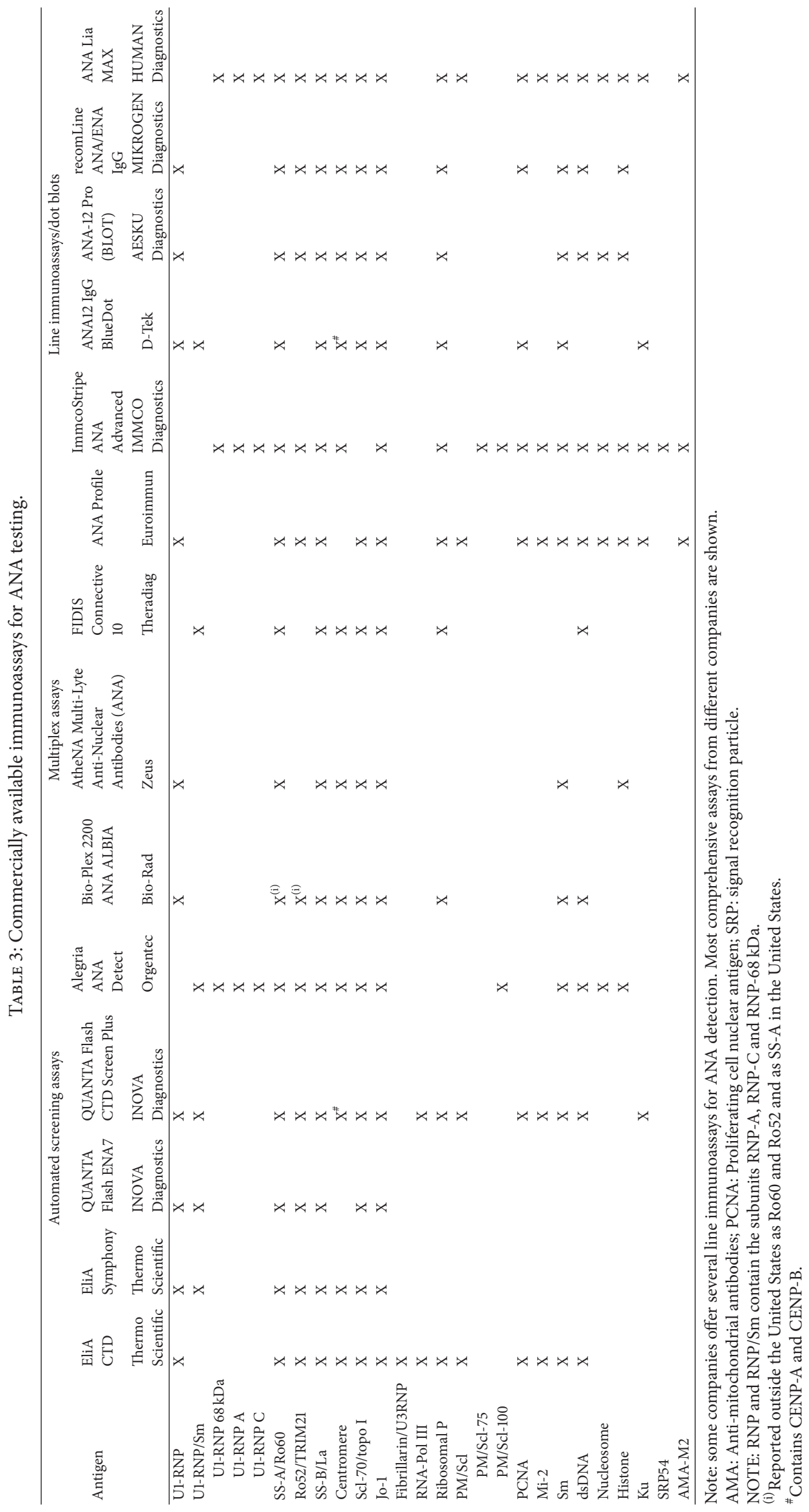


the beginning of a primary $\mathrm{SjS}$ ). A negative ANA by IIF result would reduce the probability for SLE from $10 \%$ to $<1 \%$. The third example is a young woman with photosensitivity, malar rash, and symmetrical polyarthritis. This clinical picture is suggestive of SLE (50\% probability). A positive IIF result increases the probability for SLE from $50 \%$ to $87 \%$, whereas a positive SPA CTD screen increases it to $96 \%$. A negative IIF result would reduce the probability for SLE to 7\%, whereas a negative SPA test result would reduce the probability of SLE to $21 \%$, illustrating the NPV of SPA is lower than the NPV of IIF.

\section{Nomenclature of Antibodies to Cellular Antigens Commonly Referred to as Anti-Nuclear Antibodies (ANA)}

Historically, only antibodies targeting antigens present in the nuclear compartment of the cells (nuclear antigens) were called ANA. Similarly, the term extractable nuclear antigen (ENA), described in 1959 by Holman and Robbins was used for a group of nuclear antigens extractable by saline solutions [14]. Nowadays, with the identification of a variety of new autoantigens within various compartments of the cell, the nomenclature has become rather imprecise and misleading [21]. As an oversimplification, even serum samples with anticytoplasmic but without ANA reactivity are sometimes considered as ANA positive [32-34]. This confusing terminology has even been adopted in the nomenclature of commercial autoantibody assays and kits. Autoantibody arrays on various technology platforms are often termed as ANA or ENA profiles even though they contain relatively insoluble nuclear antigens such as dsDNA and/or cytoplasmic targets such as ribosomal P or Jo-1 antigens. Therefore, standardization of this nomenclature is highly desirable.

\section{Anti-Nuclear Antibodies in Different Conditions}

To date, more than 160 autoantigens, many of them localized to the cell nucleus, have been described in sera of SLE patients [35]. Therefore, the spectrum of SLE associated autoantigens contained in most ANA screening SPA includes only a small proportion of antigens targeted by SLE autoantibodies [35, 36]. However, most SLE associated autoantigens, apart from the standard ENAs, are rarely the target of individual SLE sera and even more uncommon without reactivity to any of the standard ENAs. For example, a recent study found a sensitivity of a SPA for SLE of 79\% (in diagnostic samples) compared to a sensitivity of IIF at cut-off 1:160 of $90 \%$ [29]. Thus, the number of SLE patients having at least one clinically meaningful autoantibody that are missed by ANA SPA appears to be approximately $10 \%$. In contrast, an even larger proportion of SSc patients have a negative test results when an ANA SPA is used [37]. Consequently, the clinical utility of novel assays for different AARD can be different and each new assay has to be validated in all AARD subgroups (SLE, SSc, MCTD, SjS, and IIM).
In addition to SLE and SSc, ANA can be found in various other SARD including but not limited to IIM, SjS, and MCTD (Table 2). The appreciation that ANA are useful diagnostic biomarkers in a broad spectrum of autoimmune conditions has led to a significant change in the referral pattern of ANA tests to diagnostic laboratories (see Figure 1). Historically, primarily rheumatologists and clinical immunologists ordered ANA testing as an aid to the diagnosis of SLE. Much of this was due to the embedding of ANA and certain ENA in the older and now more recent classification criteria for SLE [38, 39]. Nowadays, a wider spectrum of clinicians order the ANA test (see Figure 1) including but not limited to internists, dermatologists, nephrologists, oncologists, cardiologists, neurologists, gastroenterologists, otolaryngologists, ophthalmologists, gynecologists, and even primary care physicians (Figure 2). This can be attributed to the broadening spectrum of ANAs in rheumatoid arthritis (RA), antiphospholipid syndrome (APS) [40], autoimmune liver diseases such as autoimmune hepatitis and primary biliary cirrhosis (PBC) [41-46], vasculitis [47], inflammatory bowel disease (IBD) [48-51], and cancer [52-57] (Table 4).

\section{Differential Diagnosis of Autoimmune Diseases}

The early and accurate diagnosis of autoimmune diseases can be very challenging because the spectrum of signs and symptoms are very wide and often overlap. Initially, an AARD has to be differentiated from a wide spectrum disorders (i.e., infections, malignancies, allergic, and adverse drug reactions) presenting with similar signs and symptoms. For example, a patient suspected to have SLE can first present with skin manifestations which need to be differentiated from discoid lupus, polymorphous light eruption, rosacea, drug eruptions, and other dermatoses. If other organs are involved (i.e., kidney, lung, musculoskeletal, cardiovascular, or neuropsychiatric [58]) the differential diagnosis must take other diagnostic possibilities into consideration. Secondly, after the presence of an AARD is confirmed on the basis of signs, symptoms, and physical examination, the different AARD need to be differentiated from each other so as to assist the clinician with decisions about appropriate therapeutic interventions. This can be further complicated by the evolution of autoimmune diseases from one condition to another. Many AARD, especially SLE, can present with arthritis but during follow-up, a diagnosis of RA or "rupus" might be established $[59,60]$. Similarly, MCTD can evolve into SSc or RA. The appropriate interpretation of a positive or negative ANA can help enlighten the diagnostic and prognostic accuracy of AARD, although very little is known about the LR to differentiate the different diseases.

\section{Screening and Profile Assays for ANA Detection}

6.1. ANA by Indirect Immunofluorescence on HEp-2 Cells. For well over the last decade, the IIF HEp-2 assay was being replaced by newer technologies for the detection of ANA [61] 


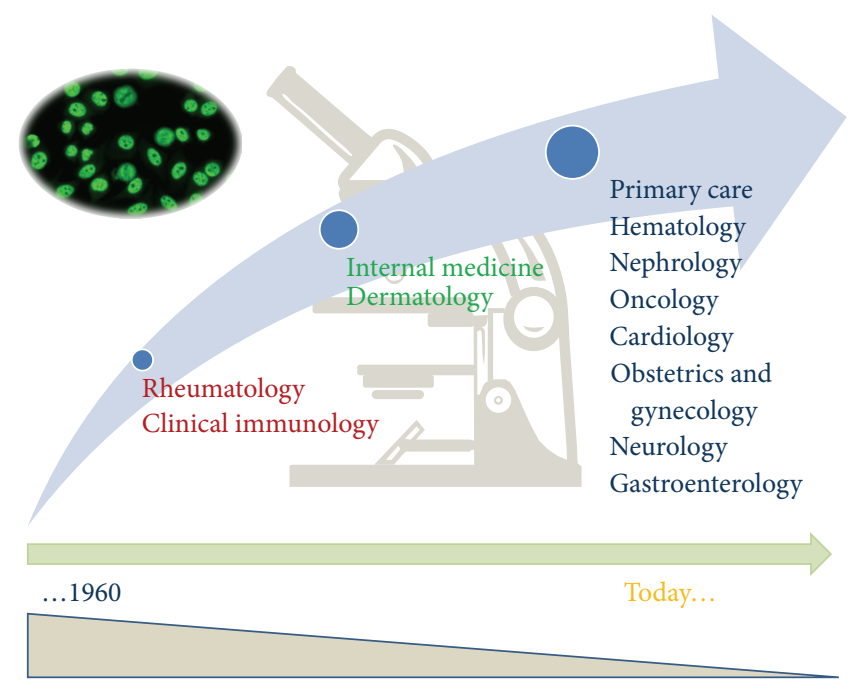

Pretest probability decreased $\rightarrow$ significant consequences on posttest probability

FIGURE 2: Change in referral patterns. Historically, when the ANA HEp-2 test became available in around 1960 exclusively rheumatologist and clinical immunologists ordered the ANA test. With the emerging recognition that many other diseases are associated with ANAs, a broad range of clinical disciplines order the ANA test. With changes in the ANA referral pattern and the associated decrease in the pretest probability, the posttest probability significantly decreases (indicated by the triangle).

TABLE 4: Clinical utility of ANA testing in different diseases.

\begin{tabular}{|c|c|c|c|c|}
\hline Diagnosis & Clinical utility & ANA prevalence & Monitoring/prognosis & Comments \\
\hline SLE & Very useful & $90-95 \%$ & Not useful & ANA IIF superior to ANA solid phase assays \\
\hline SSc & Very useful & $85-95 \%$ & Not useful & ANA IIF superior to ANA solid phase assays \\
\hline SjS & Useful & $50-60 \%$ & Not useful & $\begin{array}{l}\text { ANA solid phase assays superior to ANA IIF; SS-A } \\
\text { reactivity can be missed by ANA HEp-2 }\end{array}$ \\
\hline AIM & $\begin{array}{l}\text { Somewhat } \\
\text { useful }\end{array}$ & $50-60 \%$ & Not useful & $\begin{array}{l}\text { ANA solid phase assays superior to ANA IIF; Jo-1 } \\
\text { reactivity can be missed by ANA HEp- } 2\end{array}$ \\
\hline MCTD & Very useful & $90-100 \%$ & Not useful & $\begin{array}{l}\text { High titer anti-U1-RNP are highly indicative for } \\
\text { MCTD }\end{array}$ \\
\hline JCA/JIA & $\begin{array}{l}\text { Somewhat } \\
\text { useful }\end{array}$ & $50-60 \%$ & Very useful & Useful for subset that are at risk of developing uveitis \\
\hline $\mathrm{PBC}$ & Very useful & $50-80 \%$ & Not proven & $\begin{array}{l}\text { ANA IIF superior to solid phase assays; Antibodies } \\
\text { to SP100, gp210, nucleoporin p62, lamin B receptor } \\
\text { and Ro52 /TRIM21. Anti-gp } 210 \text { reported association } \\
\text { with poor prognosis. }\end{array}$ \\
\hline RA & Not useful & $15-20 \%$ & Not useful & $\begin{array}{l}\text { Homogeneous and speckled staining are the most } \\
\text { common patterns }\end{array}$ \\
\hline APS & Not useful & $40-70 \%$ & Not useful & $\begin{array}{l}\text { Might indicate systemic autoimmunity in primary } \\
\text { APS patients }\end{array}$ \\
\hline $\mathrm{AT}$ & Not useful & $10-20 \%$ & Not useful & $\begin{array}{l}\text { Higher in Grave's disease as compared to } \\
\text { Hashimoto's thyroiditis }\end{array}$ \\
\hline $\begin{array}{l}\text { Cancer and } \\
\text { paraneoplastic } \\
\text { syndromes }\end{array}$ & $\begin{array}{l}\text { Not useful, or } \\
\text { utility not } \\
\text { established }\end{array}$ & $20-50 \%$ & Not useful & $\begin{array}{l}\text { Antibodies to CENP-F and to other proteins might } \\
\text { be useful to help in the diagnosis of cancer; p53 has } \\
\text { been discussed; not many systematic studies on } \\
\text { ANA in cancer }\end{array}$ \\
\hline $\mathrm{AIH}$ & Useful & $40-80 \%$ & Not useful & Prevalence depends on phase of the disease \\
\hline
\end{tabular}

Abbreviations: AIH: autoimmune hepatitis; AIM: autoimmune inflammatory myopathy (polymyositis, dermatomyositis); APS: anti-phospholipid syndrome; AT: autoimmune thyroiditis; JCA/JIA: juvenile chronic arthritis/juvenile inflammatory arthritis; MCTD: mixed connective tissue disease; PBC: primary biliary cirrhosis; RA: rheumatoid arthritis; SjS: Sjögren's syndrome; SLE: systemic lupus erythematosus; SSc: systemic sclerosis NOTE: Prevalence values are based on diagnostic samples (not treated patients). 
TABle 5: Advantages and disadvantages of the HEp-2 ANA test.

\begin{tabular}{ll}
\hline Advantages & Disadvantages \\
\hline $\begin{array}{l}\text { Variety of different target autoantigens }(>100) \\
\text { Some autoantibodies can be identified without } \\
\text { confirmatory testing (i.e., anti-centromere) }\end{array}$ & Subjectivity \\
Discovery tool for novel autoantibodies & Poorly standardized across manufacturers \\
$\begin{array}{l}\text { Useful for a spectrum autoimmune diseases (i.e., } \\
\text { autoimmune hepatitis) }\end{array}$ & Requires training and expertise \\
& $\begin{array}{l}\text { Low sensitivity for certain clinically important } \\
\text { autoantibodies (i.e., Jo-1, ribosomal P, SS-A/Ro60, }\end{array}$ \\
Ro52/TRIM21) \\
Low specificity (high false positive rate)
\end{tabular}

TABLE 6: Overview of defined ANA patterns (modified from Wiik et al., 2010 [13]).

\begin{tabular}{|c|c|}
\hline Pattern group & Pattern \\
\hline \multirow{2}{*}{$\begin{array}{l}\text { Nuclear envelope } \\
\text { (membrane) }\end{array}$} & Smooth nuclear envelope \\
\hline & Punctate nuclear envelope \\
\hline \multirow{11}{*}{ Nuclear } & Homogeneous pattern \\
\hline & Large speckled \\
\hline & Coarse speckled \\
\hline & Fine speckled \\
\hline & Fine grainy Scl-70-like \\
\hline & Pleomorphic speckled (i.e., PCNA) \\
\hline & Centromere \\
\hline & Multiple nuclear dots \\
\hline & Coiled bodies (few nuclear dots) \\
\hline & Dense fine speckled \\
\hline & Isolated metaphase chromosomes \\
\hline \multirow{3}{*}{ Nucleolar } & Homogeneous nucleolar \\
\hline & Clumpy nucleolar \\
\hline & Punctate nucleolar \\
\hline \multirow{5}{*}{$\begin{array}{l}\text { Mitotic spindle } \\
\text { apparatus }\end{array}$} & Centriole (centrosome) \\
\hline & Spindle pole (NuMa) (MSA-1) (HSeg5) \\
\hline & Spindle fiber \\
\hline & Midbody (MSA-2) \\
\hline & CENP-F (MSA-3) \\
\hline \multirow{8}{*}{ Cytoplasmic } & Diffuse \\
\hline & Fine speckled \\
\hline & Mitochondrial \\
\hline & $\begin{array}{l}\text { Discrete dots: GW bodies, } \\
\text { endosomes, lysosomes }\end{array}$ \\
\hline & Golgi complex \\
\hline & Intercellular contact proteins \\
\hline & Fibers and cytoskeleton \\
\hline & Rods and rings \\
\hline
\end{tabular}

and several larger laboratories switched to automated highthroughput immunoassay platforms [61]. However, in 2010, a position paper was published indicating that IIF on HEp-2 cells should remain the "gold standard" for the detection of ANA [12], triggering a renaissance of the IIF ANA test. Nevertheless, in some cases, an ANA result based on IIF ANA on HEp-2 substrates may mislead the clinician and has to be interpreted within the clinical context [62] (Table 5). In addition, standardization of this assay is difficult due to intermanufacturer variations in the substrate and the fixation process, characteristics of the secondary antibody used [63], interlaboratory variations in microscopy apparatus, and, especially, the subjective interpretation of the results [64]. Detection of ANA by IIF may also yield false negative results even in the presence of high titers of antibodies, such as those directed to SS-A/Ro60, Ro52/TRIM21, Jo-1 (histidyl tRNA synthetase), and others [65-67]. Additionally, the challenge of significant variation of staining patterns on the ANA HEp-2 IIF substrates obtained with slides from different manufacturers [63] has led to a proposed nomenclature for IIF patterns [13] (Table 6). For these reasons, considerable effort has been dedicated to the development of standardized SPA for routine use, such as ELISA [68], which are attended by guidelines for the detection of ANA $[21,62,69]$.

6.1.1. Automated Pattern Recognition of the ANA HEp-2 Test. Computer assisted pattern recognition for ANA testing on HEp-2 cells has been described more than ten years ago [70]. Automated hardware and software-based pattern recognition platforms that allow for the identification and archiving of IIF patterns obtained on HEp-2 cell substrates; however, they have only become available during the last few years [15, $16,71-74]$. The operating principle of these new automated systems is acquiring, storing, and analyzing of digital images of stained IIF slides and displaying them on high resolution computer monitors. The inherent technical difficulties of processing and reading IIF slides (manual reading, real-time interpretation, need for dark room, and handwritten results transcription) make traditional IIF methods difficult to fit in the workflow of modern, automated laboratories. The new automated systems are powerful workflow and operational tools that can eliminate the need for a darkroom and separate image acquisition from image interpretation and have the potential to improve the quality and utility of the ANA HEp-2 assay.

The currently available automated ANA IIF image analyzing systems include NOVA View (INOVA Diagnostics, San Diego, US) [30], Aklides (Medipan, Berlin, Germany) [15, 16, 75], G-Sight (Menarini, Florence, Italy) [76, 77], 


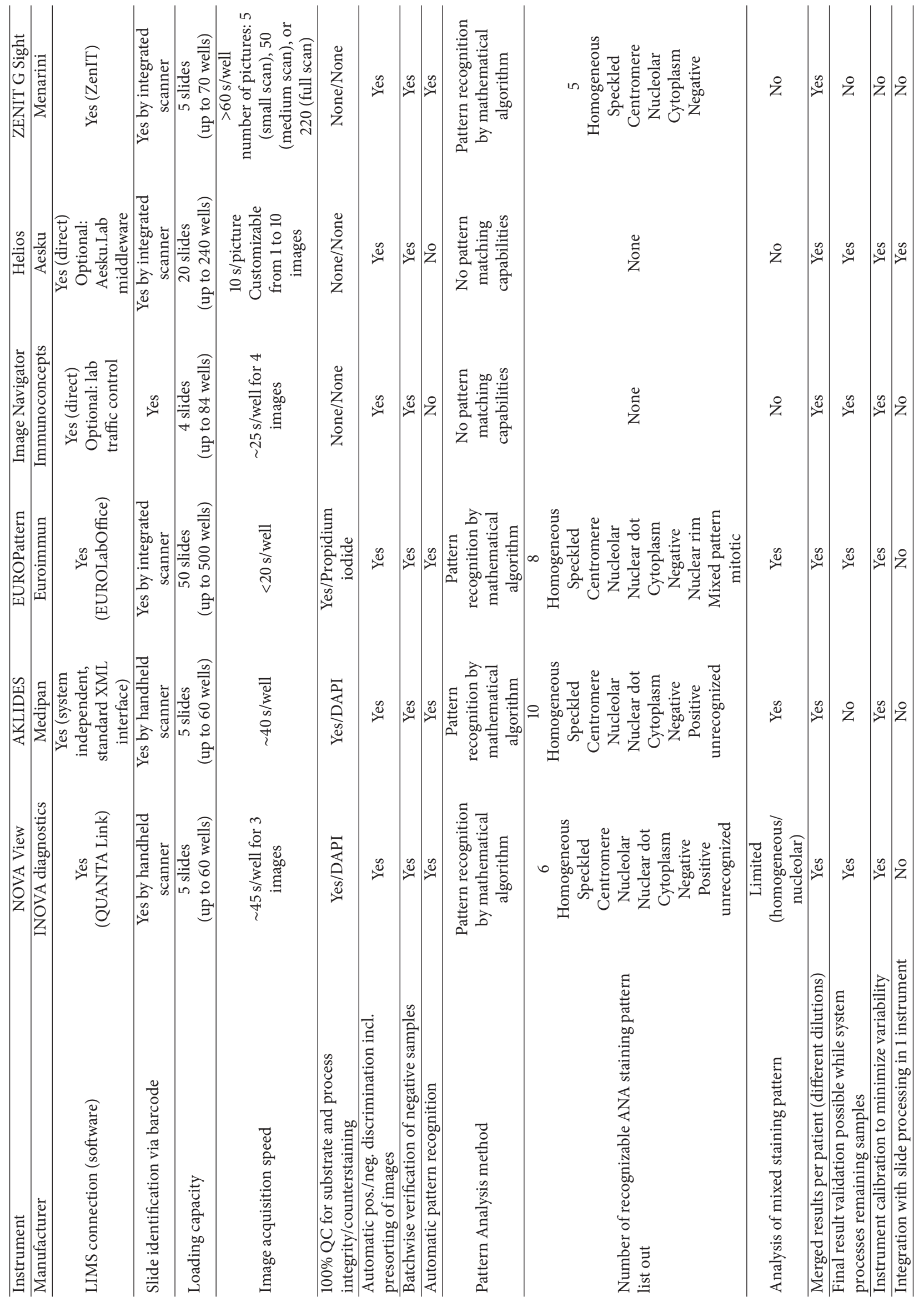


EuroPattern (Euroimmun, Lübeck, Germany) [73], Image Navigator (ImmunoConcepts, Sacramento, US), and Helios (Aesku, Wendelsheim, Germany) (Table 7). The systems differ from each other with respect to the use of DNA-binding counterstains, such as DAPI, the cell substrate used (e.g., most systems are restricted to using the respective manufacturer's slides), the throughput, the number of patterns that can be identified, and user-friendly features of the software [76, 77].

Generally, these automated systems are based on a microscope fitted with an automated stage, a CCD digital camera, a LED light source, and software that controls the moving parts and directs image acquisition. All systems perform some kind of fluorescent light intensity measurement and use the results for preliminarily categorization of the samples as positive or negative and for pattern analysis. The automated reading is followed by human visual interpretation of the digital images that are displayed on a computer monitor, allowing user confirmation or revision of the automated results. By providing good quality digital images and other objective information (such as preliminary classification and pattern interpretation), these automated systems support the operators' decision making and increase the consistency between readers and readings. In addition, the digital images can be stored for training, documentation, follow-up, and second opinion purposes. In the future, these digital images might also become part of the patient's electronic medical record (EMR). At present, the systems are highly reliable in their ability to discriminate positive from negative reactions and to estimate fluorescence intensity, but the accuracy and robustness of pattern recognition does not reach the accuracy of human interpretation $[77,78]$. An important feature is, the quality of the digital images, enabling the operators to make the same clinically relevant interpretation as they would make using a conventional microscope.

The final result interpretation is made by the operator, therefore subjectivity cannot be completely removed. Moreover, the characteristics of the HEp-2 substrates and conjugates influence the appearance of certain ANA specificities, and the automated pattern identification of the various systems is likely based on somewhat different programming principals. Nevertheless, automated systems for ANA HEp2 analysis are a significant step forward to reduce variability and offer opportunities to increase harmonization of ANA interpretation [79].

Some systems offer automated assessment of ANA endpoint titers on a single serum dilution, thereby eliminating the need for serial dilutions [75]. Moreover, the potential integration of the automated digital IIF systems with laboratory information systems (LIS) provides sample traceability, and eliminates manual transcription and associated transmittal errors, thereby improving patient safety. The systems also hold the promise to reduce hands on time. Work flow studies using different systems are required to analyze the efficiency benefits of those systems.

6.1.2. Limited Sensitivity and Specificity of ANA HEp-2 IIF Test. Several studies have demonstrated limited analytical/clinical sensitivity $[61,63,66,80,81]$ and clinical specificity [82-85], of IIF on HEp-2 cells. In particular for anti-Rib-P, antiSSA/Ro60, and anti-Jo-1 autoantibodies, the ANA HEp-2 IIF test has been reported to lack analytical sensitivity which translates to the clinical sensitivity for AARD $[63,65,66,81$, $86,87]$. In a comparative analysis of an ANA ELISA and ANA IIF, equivalent sensitivity but significantly higher specificity of the ELISA was observed [84]. When using the cut-off recommended by the manufacturer, the clinical specificity of IIF for AARD was as low as $62.3 \%$ [84].

Based on these observations, over three decades ago a transfected HEp-2 cell line overexpressing SS-A/Ro60 was developed and this cell-based IIF assay is marketed as HEp2000 cells [81, 88-90]. A similar approach has recently been used for SmD1 antigen in a research HEp-2 cell line [91]. This technological approach of overexpressing target antigens in a variety of cell lines has more recently become a productive approach to cell based IIF assays where structural or conformational epitopes are important for human autoantibody detection. It was found that adding antigen specific assays to IIF on HEp-2 cells significantly improved the diagnostic algorithm for the diagnosis of SARD [92]. However, it was concluded in this study that changing from IIF to other methods for ANA detection also required modification of the disease criteria. In addition, it was highly recommended to use anti-SS-A antibody assays in addition to ANA HEp-2 test [92].

6.2. Different Staining Patterns Have Different Specificities. Disease classification criteria, such as the SLE criteria [38, 39], do not distinguish between different ANA IIF patterns. Although certain ANA patterns on HEp-2 cells have a significant disease associations, in clinical practice differentiation of IIF patterns is rarely used as an aid in establishing the clinical diagnosis [21]. Nevertheless, it is well established that the centromere staining pattern is primarily associated with the limited cutaneous form of SSc (also referred to as the CREST syndrome) [8,93]. Additional examples are the association of the homogenous IIF pattern with SLE and nucleolar IIF pattern with SSc [37], although these generalizations have not been observed in all studies [94] (most likely attributed to different pretest probabilities). Interestingly, antibodies to dense fine speckled 70 (DFS70), also known as LEDGF (lens epithelium-derived growth factor), which generate a DFS IIF pattern on HEp-2 cells were not commonly observed in AARDs [82, 95-102]. These antibodies decorate interphase nucleoplasm outside of the nucleolus but in contrast to the anti-SSA/SSB and antiMi-2 antibodies, the anti-DFS70/LEDGF antibodies stain the metaphase and telophase chromosomal cell plates [13] (Figure 3). Just recently, it was confirmed that the DFS pattern was not associated with AARD and was primarily found in apparently healthy individuals [103]. In rare cases, this pattern can also be observed in patients with AARD, but these cases, anti-DFS70 antibodies are commonly accompanied by other autoantibodies $[98,102]$. Follow-up of individuals with high titers of anti-DFS70 antibodies revealed that they retain ANA reactivity even after four years but do not develop SARD $[103,104]$. Hence, it has been suggested that, within some 


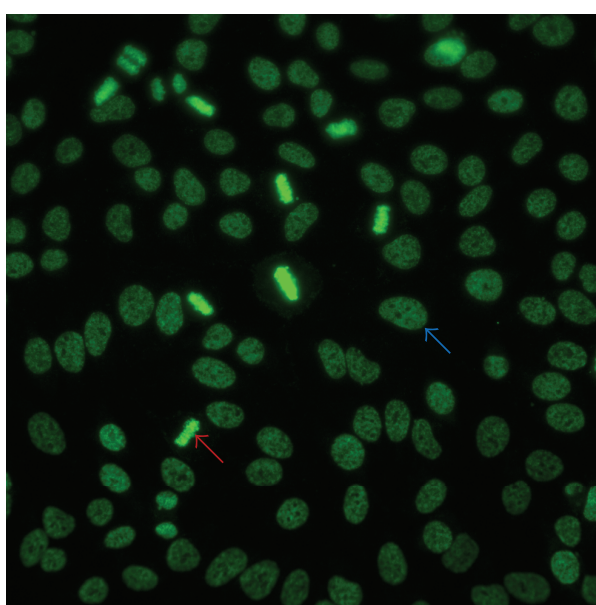

(a)

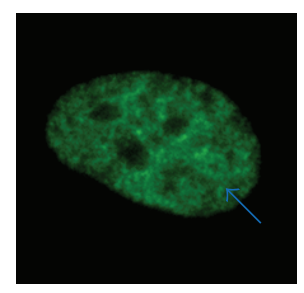

(b)

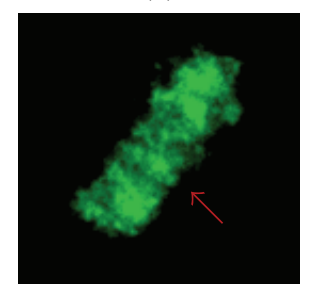

(c)

FIgURE 3: Characteristic staining pattern of anti-DFS70 antibodies. The characteristic dense fine speckled (DFS) staining pattern of interphase HEp-2 cells is indicated by the blue arrow and the strong chromatin staining of mitotic cells by the red arrow. (a) Wide field view using 40x magnification, (b) dense fine speckled pattern of an interphase nucleus, and (c) of the metaphase chromatin of a mitotic cell.

limits, anti-DFS70 antibodies can be used to exclude the diagnosis of AARD [82]. The major epitope of the molecule is conformation dependent and is located in the C-terminal part of the molecule [105]. Although the immunoreactive region has been shown to be located within a stretch of 22 amino acids (407-435), the use of 12 mer peptides failed to establish reactivity with the presumed linear epitope [105].

6.3. ANA Screening ELISA. During the last decade, different strategies have been utilized to develop, evaluate, and commercialize several ANA screening ELISAs [106-110]. The majority of ANA screening ELISAs make use of mixtures or "blends" of purified autoantigens from native sources and/or recombinant technologies $[106,111]$. The composition of these antigen preparations is quite diverse and is dependent on several factors including the availability of pure antigens and the technical feasibility of combining all different antigens in a single assay. Most available immunoassays contain SSA/Ro60 [112], SS-B/La, Scl-70/topoisomerase I [113], CENPB [93], Jo-1, U1-RNP, Sm, and dsDNA [114]. ANA screening ELISAs from some manufacturers also contain other autoantigens such as $\mathrm{PM} / \mathrm{Scl}$ or ribosomal P [36]. However, based on comparison to immunoprecipitation of radiolabelled native proteins and other techniques, reactivity can be missed by these ELISAs even if the autoantigens are contained in the mixture [36]. This can be attributed to the notion that individual autoantigens exhibit different biochemical properties and, therefore, display different binding behaviors when solid phase matrices are used to bind the target autoantigens. For example, some antigens might bind to other targets in the same mixture resulting in a masking effect that gives the impression that insufficient epitopes are available for human autoantibody binding. Some antigens, such as PCNA $[115,116]$, RNA Pol III [117], or Th/To [118], are rarely included as purified antigen in screening assays.
6.4. Line Immunoassays. Line immunoassays (LIA) can basically be considered second generation dot-blot assays. A broad range of LIAs are available and they are typically used to confirm autoantibodies previously identified by HEp-2 ANA IIF or other screening immunoassays [119]. However, in some laboratories, these LIAs have also been used as a screening test for disease specific autoantibodies that are seen in SLE, SSc, IIM, paraneoplastic, and autoimmune liver diseases [120]. There have been recent advances in partially automating these multiplex LIAs making them somewhat more appealing to high throughput laboratory testing [121]. Despite their ease of use, LIAs have some drawbacks including the lack of sensitivity and specificity for certain autoantibodies [120, 122]. The antigen compositions of several are shown in Table 3.

6.5. Multiplex Bead-Based Assays. Multiplex assays based on the Luminex technology (Austin, Texas, USA) use addressable laser beads and are therefore often referred to as ALBIA (addressable laser bead immunoassays) [9]. Today, several commercial ALBIA kits are available for the detection of autoantibodies to a variety of autoantigens $[83,85,123-130]$. First generation ALBIAs showed polyreactivity which was caused by nonspecific binding to the beads [131]. Second generation assays showed significant reduced polyreactivity and thus higher specificity [131]. In 2007, a multiplex test for the detection of ANA was compared to ANA IIF and different ELISA assays. 7/87 (7.4\%) of healthy donors were positive, $6 / 7$ showed a speckled, and 1/7 a nucleolar staining pattern [85]. Similar to LIAs, the number of antigens and the antigen compositions of these bead-based arrays significantly vary and are shown in Table 3.

6.6. Other ANA Tests. Additional methods have been developed for automated ANA detection [84, 108, 132-139]. In 
1999, a fully automated ANA screening assay (COBAS Core HEp2 ANA EIA; Roche Diagnostics, Mannheim, Germany) was developed and evaluated. The performance evaluation studies showed promising results but were inclusive in the conclusion. One study shows that the new assay is superior to the ANA IIF as analyzed by ROC analysis [138]. However, this finding could not be confirmed in a second independent analysis [133]. Six years later, the first-automated chemiluminescent immunoassay (CIA) for the detection of ANA (LIAISON ANA screen, DiaSorin) was evaluated in two centers yielding a good positive (79.5\%) and negative agreement (91.2\%) when the LIAISON ANA screen was compared to the ANA IIF test (Bio-Rad) [140]. A recent study using this assay showed ANA prevalence compatible with the expected values of the ANA IIF test [42]. Only moderate agreement was found between IIF and a multiplex assay based on the ALBIA. The majority of ANA IIF positive and multiplex ANA negative sera were also positive by an ANA ELISA utilizing nuclear extracts [129]. In addition, several other methods have been developed for ANA testing, but are not widely used in clinical practice. In 2009, a novel method for quantitative ANA measurement using near-infrared imaging was also described [141]. Furthermore, a novel microbead-based ELISA system using fluorescence-coded immobilized microbeads on the AKLIDIS system has been described [142]. Similar to the ALBIA, but using nanobarcodes for the bead identification, the Ultraplex system [143] was used to screen simultaneously for nine ANA autoantibodies, requiring significantly less labor and fewer reagents, with performance equivalent to existing gold-standard methods.

Several publications have described protein arrays on planar solid phase surfaces for the detection of autoantibodies to a wide range of viral proteins and autoantigens $[144,145]$ bound to a variety of surfaces [146]. However, these immunoassays are still not used in routine diagnostic laboratories.

More recently novel "ANA" screening assays have been developed on fully automated closed systems such as the Phadia (Thermo Fisher, Freiburg, Germany) or the BIOFLASH System (INOVA, San Diego, USA) [147]. The EliA CTD Screen (Thermo Fisher) has been evaluated in several studies, two of which have been published in peer-reviewed journals $[28,148]$. The first study showed satisfactory results for anti-ribosomal $\mathrm{P}$, anti-PM/Scl, anti-Mi-2, and anti-PCNA antibodies. However, the sensitivity for anti-fibrillarin and anti-RNA Pol III antibodies was rather limited [148]. In the second study, the CTD screen was compared to the ANA HEp-2000 method [29]. Additionally, the QUANTA Flash CTD Screen Plus (on BIO-FLASH) was evaluated and shown to exhibit good sensitivity in different SARD [149]. However, further studies are needed to establish the clinical performance characteristics of the novel assays.

\section{Quality Aspects, Standardization, and Reference Sera}

For the development and quality assurance of autoantibody assays a broad range of international reference samples are mandatory $[150,151]$. Consequently, an ANA and related autoantibody reference serum panel was established and is now available through the Center for Disease Control and Prevention in Atlanta, USA [152-155]. Initially, this panel of sera was used to standardize ANA IIF tests and to define staining patterns, but eventually, this panel was used to evaluate the performance of different autoantibody immunoassays [152]. In 2000, another ANA reference serum panel became available through the Association of Medical Laboratory Immunologists (AMLI) [156]. However, only a few studies used these samples for their investigations [157]. The first international standard for ANA became available in 1990 [158]. However, the number of international reference sera is limited and not all autoantibodies are represented by the available serum panels [150]. Furthermore, for screening assays, monospecific samples for each antigen are required to ensure the presence of all antigens in sufficient quantity and quality.

Different committees and organizations were formed who worked to achieve a better standardized approach to autoantibody testing $[150,159,160]$ including the International Union of Immunology Specialties (IUIS) Autoantibody Standardization Committee (http://asc.dental.ufl.edu/home .html\#text), the European Autoimmunity Stand-ardisation Initiative (EASI) [http://www.easi-network.com/], and the Working Group on Harmonization of Autoantibody Tests (WG-HAT) in the framework of the International Federation of Clinical Chemistry and Laboratory Medicine [http://www .ifcc.org/ifcc-scientific-division/sd-working-groups/harmoonisation-of-autoantibody-tests-wg-hat/]. Despite significant efforts to standardize autoantibody tests $[152,161]$ and evidence that these groups are now working more closely together, [21] significant variations still exist.

\section{Conclusions}

(i) Performance data (including LRs) of the method used to detect ANA and appropriate explanation should be made available to the clinician.

(ii) ANA test results are only a portion of the information that aids in the diagnosis of systemic autoimmune diseases and are an adjunct to the clinician's diagnostic repertoire.

(iii) Both IIF on HEp-2 cells and solid phase immunoassays have their individual advantages and limitations.

(iv) Standardized nomenclature of diseases and associated autoantibodies is an important goal for immediate consideration by advisory groups.

\section{Future Perspectives}

Despite significant evolution and improvements in ANA and related autoantibody testing, including the arrival of novel and promising technologies, several limitations still persist and need to be addressed. First, the terminology and nomenclature used to identify and refer to various autoantibodies need to be standardized. Second, the classification criteria and nomenclature of individual SARD 
and related autoimmune diseases must continue to evolve and keep abreast of biomarker identification. Third, the corresponding immunoassays and diagnostic platforms used for the various clinical applications need to be based on standardized reference samples of defined specificities. This possibility could include the development and validation of disease specific screening assays (i.e., SLE Screen, SSc Screen) on solid phase technologies. Fourth, a clearly defined strategy needs to be developed to facilitate clinicians and laboratory scientists alike becoming more familiar with and be able to intelligently use objective interpretation of autoantibody results through an understanding of ROCs and LRs. Lastly, diagnostic algorithms need to be adjusted to the clinical and laboratory setting considering the referral pattern, the sample testing volume, and health economic aspects (i.e., reimbursement).

\section{Conflict of Interests}

Michael Mahler is employed at INOVA Diagnostics, a company that manufactures and markets autoantibody assays. Pier-Luigi Meroni received fees as consultant for INOVA Diagnostics and from BioRad. Xavier Bossuyt has been a consultant to INOVA Diagnostics and has received lecture fees from Instrumentation Laboratory, Thermo Fisher, and Menarini. Marvin J. Fritzler is the Director of Mitogen Advanced Diagnostics Laboratory (Calgary, Alberta, Canada) which performs autoantibody testing and is also a consultant to INOVA Diagnostics, and has received gifts in kind from Euroimmun GmbH.

\section{References}

[1] A. H. Coons and M. H. Kaplan, "Localization of antigen in tissue cells; improvements in a method for the detection of antigen by means of fluorescent antibody," The Journal of Experimental Medicine, vol. 91, no. 1, pp. 1-13, 1950.

[2] G. J. Friou, S. C. Finch, and K. D. Detre, "Interaction of nuclei and globulin from lupus erythematosis serum demonstrated with fluorescent antibody," Journal of Immunology, vol. 80, no. 4, pp. 324-329, 1958.

[3] G. J. Friou, "Setting the scene: a historical and personal view of immunologic diseases, autoimmunity and ANA," Clinical and Experimental Rheumatology, vol. 12, supplement 11, pp. S23S25, 1994.

[4] M. M. Hargraves, H. Richmond, and R. Morton, "Presentation of two bone marrow elements, the tart cell and the L.E. cell," Proceedings of the Staff Meetings of the Mayo Clinic, vol. 23, pp. 25-28, 1948.

[5] H. R. Holman, H. R. Deicher, and H. G. Kunkel, "The L. E. cell and the L. E. serum factors," Bulletin of the New York Academy of Medicine, vol. 35, no. 7, pp. 409-418, 1959.

[6] A. E. Moore, L. Sabachewsky, and H. W. Toolan, "Culture characteristics of four permanent lines of human cancer cells," Cancer Research, vol. 15, pp. 598-602, 1955.

[7] E. M. Tan, "Antinuclear antibodies in diagnosis and management," Hospital Practice, vol. 18, no. 1, pp. 79-84, 1983.

[8] M. Mahler and M. J. Fritzler, "Epitope specificity and significance in systemic autoimmune diseases," Annals of the New York Academy of Sciences, vol. 1183, pp. 267-287, 2010.
[9] M. J. Fritzler and M. L. Fritzler, "The emergence of multiplexed technologies as diagnostic platforms in systemic autoimmune diseases," Current Medicinal Chemistry, vol. 13, no. 21, pp. 25032512, 2006.

[10] M. J. Fritzler, "Advances and applications of multiplexed diagnostic technologies in autoimmune diseases," Lupus, vol. 15, no. 7, pp. 422-427, 2006.

[11] A. S. Wiik, T. P. Gordon, A. F. Kavanaugh et al., Eds., "Cutting edge diagnostics in rheumatology: the role of patients, clinicians, and laboratory scientists in optimizing the use of autoimmune serology," Arthritis Care and Research, vol. 51, no. 2, pp. 291-298, 2004.

[12] P. L. Meroni and P. H. Schur, "ANA screening: an old test with new recommendations," Annals of the Rheumatic Diseases, vol. 69, no. 8, pp. 1420-1422, 2010.

[13] A. S. Wiik, M. Høier-Madsen, J. Forslid, P. Charles, and J. Meyrowitsch, "Antinuclear antibodies: a contemporary nomenclature using HEp-2 cells," Journal of Autoimmunity, vol. 35, no. 3, pp. 276-290, 2010.

[14] H. Holman and W. Robbins, "Antinuclear antibodies in systemic lupus erythematosus," Arthritis \& Rheumatology, vol. 2, pp. 468-471, 1959.

[15] K. Egerer, D. Roggenbuck, R. Hiemann et al., "Automated evaluation of autoantibodies on human epithelial-2 cells as an approach to standardize cell-based immunofluorescence tests," Arthritis Research and Therapy, vol. 12, no. 2, article R40, 2010.

[16] S. Kivity, B. Gilburd, N. Agmon-Levin et al., "A novel automated indirect immunofluorescence autoantibody evaluation," Clinical Rheumatology, vol. 31, no. 3, pp. 503-509, 2012.

[17] A. Melegari, C. Bonaguri, A. Russo, B. Luisita, T. Trenti, and G. Lippi, "A comparative study on the reliability of an automated system for the evaluation of cell-based indirect immunofluorescence," Autoimmunity Reviews, vol. 11, pp. 713716, 2012.

[18] M. R. Arbuckle, M. T. McClain, M. V. Rubertone et al., "Development of autoantibodies before the clinical onset of systemic lupus erythematosus," The New England Journal of Medicine, vol. 349, no. 16, pp. 1526-1533, 2003.

[19] C. Eriksson, H. Kokkonen, M. Johansson, G. Hallmans, G. Wadell, and S. Rantapää-Dahlqvist, "Autoantibodies predate the onset of systemic lupus erythematosus in northern Sweden," Arthritis Research and Therapy, vol. 13, no. 1, article R30, 2011.

[20] T. Kampfrath and S. S. Levinson, "Brief critical review: statistical assessment of biomarker performance," Clinica Chimica Acta, vol. 419, pp. 102-107, 2013.

[21] N. Agmon-Levin, J. Damoiseaux, C. Kallenberg et al., "International recommendations for the assessment of autoantibodies to cellular antigens referred to as anti-nuclear antibodies," Annals of Rheumatic Diseases, vol. 73, pp. 17-23, 2014.

[22] A. M. Abeles and M. Abeles, "The clinical utility of a positive antinuclear antibody test result," American Journal of Medicine, vol. 126, pp. 342-348, 2013.

[23] E. M. Tan, T. E. W. Feltkamp, J. S. Smolen et al., "Range of antinuclear antibodies in "healthy" individuals," Arthritis \& Rheumatism, vol. 40, no. 9, pp. 1601-1611, 1997.

[24] D. A. González, A. C. D. León, A. R. Varela et al., "Autoantibody detection with indirect immunofluorescence on HEp-2 cells: starting serum dilutions for systemic rheumatic diseases," Immunology Letters, vol. 140, no. 1-2, pp. 30-35, 2011.

[25] X. Bossuyt, "Clinical performance characteristics of a laboratory test. A practical approach in the autoimmune laboratory," Autoimmunity Reviews, vol. 8, no. 7, pp. 543-548, 2009. 
[26] P. Vermeersch and X. Bossuyt, "Comparative analysis of different approaches to report diagnostic accuracy," Archives of Internal Medicine, vol. 170, no. 8, pp. 734-735, 2010.

[27] A. F. Kavanaugh, D. H. Solomon, P. Schur, J. D. Reveille, Y. R. S. Sherrer, and R. Lahita, "Guidelines for immunologic laboratory testing in the rheumatic diseases: an introduction," Arthritis Care and Research, vol. 47, no. 4, pp. 429-433, 2002.

[28] K. Op De Beeck, P. Vermeersch, P. Verschueren et al., "Detection of antinuclear antibodies by indirect immunofluorescence and by solid phase assay," Autoimmunity Reviews, vol. 10, no. 12, pp. 801-808, 2011.

[29] K. Op De Beéck, P. Vermeersch, P. Verschueren et al., "Antinuclear antibody detection by automated multiplex immunoassay in untreated patients at the time of diagnosis," Autoimmunity Reviews, vol. 12, pp. 137-143, 2012.

[30] S. Schouwers, M. Bonnet, P. Verschueren et al., "Value-added reporting of antinuclear antibody testing by automated indirect immunofluorescence analysis," Clinical Chemistry and Laboratory Medicine, vol. 52, no. 4, pp. 547-551, 2014.

[31] X. Bossuyt and S. Fieuws, "Detection of antinuclear antibodies: added value of solid phase assay?" Annals of the Rheumatic Diseases, vol. 73, article e10, 2014.

[32] M. Vercammen, P. Meirlaen, J. Sennesael et al., "Diagnostic accuracy of the FIDIS multiplex fluorescent microsphere immunodetection system for anti-extractable nuclear antigen (ENA) antibodies in connective tissue diseases," Clinical Chemistry and Laboratory Medicine, vol. 45, no. 4, pp. 505-512, 2007.

[33] J. Wenzel, R. Gerdsen, M. Uerlich, R. Bauer, T. Bieber, and I. Boehm, "Antibodies targeting extractable nuclear antigens: historical development and current knowledge," British Journal of Dermatology, vol. 145, no. 6, pp. 859-867, 2001.

[34] J. G. M. C. Damoiseaux and J. W. Cohen Tervaert, "From ANA to ENA: how to proceed?" Autoimmunity Reviews, vol. 5, no. 1, pp. 10-17, 2006.

[35] Y. Sherer, A. Gorstein, M. J. Fritzler, and Y. Shoenfeld, "Autoantibody explosion in systemic lupus erythematosus: more than 100 different antibodies found in SLE patients," Seminars in Arthritis and Rheumatism, vol. 34, no. 2, pp. 501-537, 2004.

[36] S. S. Copple, A. D. Sawitzke, A. M. Wilson, A. E. Tebo, and H. R. Hill, "Enzyme-linked immunosorbent assay screening then indirect immunofluorescence confirmation of antinuclear antibodies," American Journal of Clinical Pathology, vol. 135, no. 5, pp. 678-684, 2011.

[37] V. K. Shanmugam, D. R. Swistowski, N. Saddic, H. Wang, and V. D. Steen, "Comparison of indirect immunofluorescence and multiplex antinuclear antibody screening in systemic sclerosis," Clinical Rheumatology, vol. 30, no. 10, pp. 1363-1368, 2011.

[38] E. M. Tan, A. S. Cohen, and J. F. Fries, "The 1982 revised criteria for the classification of systemic lupus erythrematosus," Arthritis \& Rheumatism, vol. 25, no. 11, pp. 1271-1277, 1982.

[39] M. Petri, A. M. Orbai, G. S. Alarcon et al., "Derivation and validation of the systemic lupus international collaborating clinics classification criteria for systemic lupus erythematosus," Arthritis \& Rheumatology, vol. 64, pp. 2677-2686, 2012.

[40] L. Andreoli, F. Pregnolato, R. W. Burlingame et al., "Antinucleosome antibodies in primary antiphospholipid syndrome: a hint at systemic autoimmunity?" Journal of Autoimmunity, vol. 30, no. 1-2, pp. 51-57, 2008.

[41] S. Assassi, M. J. Fritzler, F. C. Arnett et al., "Primary biliary cirrhosis (PBC), PBC autoantibodies, and hepatic parameter abnormalities in a large population of systemic sclerosis patients," Journal of Rheumatology, vol. 36, no. 10, pp. 22502256, 2009.

[42] Y. Zafrir, B. Gilburd, M. G. Carrasco et al., "Evaluation of an automated chemiluminescent immunoassay kit for antinuclear antibodies in autoimmune diseases," Immunologic Research, vol. 56, pp. 451-456, 2013.

[43] A. Granito, P. Muratori, C. Quarneti, G. Pappas, R. Cicola, and L. Muratori, "Antinuclear antibodies as ancillary markers in primary biliary cirrhosis," Expert Review of Molecular Diagnostics, vol. 12, no. 1, pp. 65-74, 2012.

[44] P. Muratori, A. Granito, G. Pappas, L. Muratori, M. Lenzi, and F. B. Bianchi, "Autoimmune liver disease 2007," Molecular Aspects of Medicine, vol. 29, no. 1-2, pp. 96-102, 2008.

[45] D. P. Bogdanos and L. Komorowski, "Disease-specific autoantibodies in primary biliary cirrhosis," Clinica Chimica Acta, vol. 412, no. 7-8, pp. 502-512, 2011.

[46] N. Agmon-Levin, Y. Shapira, C. Selmi et al., "A comprehensive evaluation of serum autoantibodies in primary biliary cirrhosis," Journal of Autoimmunity, vol. 34, no. 1, pp. 55-58, 2010.

[47] J. A. Savige, M. Gallicchio, L. Chang, and J. D. Parkin, "Autoantibodies in systemic vasculitis," Australian and New Zealand Journal of Medicine, vol. 21, no. 4, pp. 433-437, 1991.

[48] F. Beigel, F. Schnitzler, R. Paul Laubender et al., "Formation of antinuclear and double-strand DNA antibodies and frequency of lupus-like syndrome in anti-TNF- $\alpha$ antibody-treated patients with inflammatory bowel disease," Inflammatory Bowel Diseases, vol. 17, no. 1, pp. 91-98, 2011.

[49] C. Mancho, Á. Sainz, M. García-Sancho, A. Villaescusa, M. A. Tesouro, and F. Rodríguez-Franco, "Detection of perinuclear antineutrophil cytoplasmic antibodies and antinuclear antibodies in the diagnosis of canine inflammatory bowel disease," Journal of Veterinary Diagnostic Investigation, vol. 22, no. 4, pp. 553-558, 2010.

[50] H. Nielsen, A. Wiik, and J. Elmgreen, "Granulocyte specific antinuclear antibodies in ulcerative colitis: Aid in differential diagnosis of inflammatory bowel disease," Acta Pathologica Microbiologica et Immunologica Scandinavica: C Immunology, vol. 91, no. 1, pp. 23-26, 1983.

[51] D. Zauli, C. Crespi, and P. Dall'Amore, "Antibodies to the cytoskeleton components and other autoantibodies in inflammatory bowel disease," Digestion, vol. 32, no. 2, pp. 140-144, 1985.

[52] A. K. Al-Shukaili, A. A. Al-Jabri, and M. S. Al-Moundhari, "Prognostic value of auto-antibodies in the serum of Omani patients with gastric cancer," Saudi Medical Journal, vol. 27, no. 12, pp. 1873-1877, 2006.

[53] J. B. Armas, J. Dantas, D. Mendonça et al., "Anticardiolipin and antinuclear antibodies in cancer patients-a case control study," Clinical and Experimental Rheumatology, vol. 18, no. 2, pp. 227232, 2000.

[54] F. Blaes, M. Klotz, H. Huwer et al., "Antineural and antinuclear autoantibodies are of prognostic relevance in non-small cell lung cancer," Annals of Thoracic Surgery, vol. 69, no. 1, pp. 254$258,2000$.

[55] T. Daniels, J. Zhang, I. Gutierrez et al., "Antinuclear autoantibodies in prostate cancer: immunity to LEDGF/p75, a survival protein highly expressed in prostate tumors and cleaved during apoptosis," Prostate, vol. 62, no. 1, pp. 14-26, 2005.

[56] H. Imai, Y. Nakano, K. Kiyosawa, and E. M. Tan, "Increasing titers and changing specificities of antinuclear antibodies in patients with chronic liver disease who develop hepatocellular carcinoma," Cancer, vol. 71, pp. 26-35, 1993. 
[57] A. Imran, F. Neelam, and M. Tariq, "Incidence of circulating antinuclear antibodies in cancer patients," Indian journal of medical sciences, vol. 57, no. 3, pp. 113-116, 2003.

[58] A. M. Borowoy, J. E. Pope, E. Silverman et al., "Neuropsychiatric lupus: the prevalence and autoantibody associations depend on the definition: results from the 1000 faces of lupus cohort," Seminars in Arthritis and Rheumatism, vol. 42, pp. 179-185, 2012.

[59] A. Fernández, G. Quintana, E. L. Matteson et al., "Lupus arthropathy: historical evolution from deforming arthritis to rhupus," Clinical Rheumatology, vol. 23, no. 6, pp. 523-526, 2004.

[60] C. Tani, D. D’Aniello, S. A. Delle et al., "Rhupus syndrome: assessment of its prevalence and its clinical and instrumental characteristics in a prospective cohort of 103 SLE patients," Autoimmunity Reviews, vol. 12, pp. 537-541, 2013.

[61] H. Nossent and O. P. Rekvig, "Antinuclear antibody screening in this new millennium: farewell to the microscope?" Scandinavian Journal of Rheumatology, vol. 30, no. 3, pp. 123-126, 2001.

[62] A. Kavanaugh, R. Tomar, J. Reveille, D. H. Solomon, and H. A. Homburger, "Guidelines for clinical use of the antinuclear antibody test and tests for specific autoantibodies to nuclear antigens," Archives of Pathology and Laboratory Medicine, vol. 124, no. 1, pp. 71-81, 2000.

[63] M. Mahler, J. T. Ngo, J. Schulte-Pelkum, T. Luettich, and M. J. Fritzler, "Limited reliability of the indirect immunofluorescence technique for the detection of anti-Rib-P antibodies," Arthritis Research and Therapy, vol. 10, no. 6, article R131, 2008.

[64] I. Kang, R. Siperstein, T. Quan, and M. L. Breitenstein, "Utility of age, gender, ANA titer and pattern as predictors of anti-ENA and -dsDNA antibodies," Clinical Rheumatology, vol. 23, no. 6, pp. 509-515, 2004.

[65] X. Bossuyt and A. Luyckx, "Antibodies to extractable nuclear antigens in antinuclear antibody-negative samples," Clinical Chemistry, vol. 51, no. 12, pp. 2426-2427, 2005.

[66] I. E. A. Hoffman, I. Peene, E. M. Veys, and F. De Keyser, "Detection of specific antinuclear reactivities in patients with negative anti-nuclear antibody immunofluorescence screening tests," Clinical Chemistry, vol. 48, no. 12, pp. 2171-2176, 2002.

[67] X. Bossuyt, G. Mariën, and S. Vanderschueren, "A 67-year-old woman with a systemic inflammatory syndrome and sicca," Clinical Chemistry, vol. 56, no. 9, pp. 1508-1509, 2010.

[68] G. P. Tri, R. C. W. Wong, and S. Adelstein, "Autoantibodies to extractable nuclear antigens: making detection and interpretation more meaningful," Clinical and Diagnostic Laboratory Immunology, vol. 9, no. 1, pp. 1-7, 2002.

[69] D. H. Solomon, A. J. Kavanaugh, P. H. Schur et al., "Evidencebased guidelines for the use of immunologic tests: antinuclear antibody testing," Arthritis Care and Research, vol. 47, no. 4, pp. 434-444, 2002.

[70] P. Perner, H. Perner, and B. Müller, "Mining knowledge for HEp-2 cell image classification," Artificial Intelligence in Medicine, vol. 26, no. 1-2, pp. 161-173, 2002.

[71] R. Hiemann, T. Büttner, T. Krieger, D. Roggenbuck, U. Sack, and K. Conrad, "Challenges of automated screening and differentiation of non-organ specific autoantibodies on HEp-2 cells," Autoimmunity Reviews, vol. 9, no. 1, pp. 17-22, 2009.

[72] A. Willitzki, R. Hiemann, V. Peters et al., "New platform technology for comprehensive serological diagnostics of autoimmune diseases," Clinical and Developmental Immunology, vol. 2012, Article ID 284740, 8 pages, 2012.
[73] J. Voigt, C. Krause, E. Rohwader et al., "Automated indirect immunofluorescence evaluation of antinuclear autoantibodies on HEp-2 cells," Clinical and Developmental Immunology, vol. 2012, Article ID 651058, 7 pages, 2012.

[74] D. Bertin, N. Jourde-Chiche, P. Bongrand, and N. Bardin, "Original approach for automated quantification of antinuclear autoantibodies by indirect immunofluorescence," Clinical and Developmental Immunology, vol. 2013, Article ID 182172, 8 pages, 2013.

[75] D. Roggenbuck, R. Hiemann, P. Schierack, D. Reinhold, and K. Conrad, "Digital immunofluorescence enables automated detection of antinuclear antibody endpoint titers avoiding serial dilution," Clinical Chemistry and Laboratory Medicine, pp. 1-3, 2013.

[76] C. Bonroy, C. Verfaillie, V. Smith et al., "Automated indirect immunofluorescence antinuclear antibody analysis is a standardized alternative for visual microscope interpretation," Clinical Chemistry and Laboratory Medicine, vol. 51, pp. 17711779, 2013.

[77] X. Bossuyt, S. Cooreman, B. H. De et al., "Detection of antinuclear antibodies by automated indirect immunofluorescence analysis," Clinica Chimica Acta, vol. 415, pp. 101-106, 2013.

[78] P. Foggia, G. Percannella, P. Soda, and M. Vento, "Benchmarking HEp-2 cells classification methods," IEEE Transactions on Medical Imaging, vol. 32, pp. 1878-1889, 2013.

[79] D. Roggenbuck, R. Hiemann, D. Bogdanos, D. Reinhold, and K. Conrad, "Standardization of automated interpretation of immunofluorescence tests," Clinica Chimica Acta, vol. 421, pp. 168-169, 2013.

[80] K. Kidd, K. Cusi, R. Mueller, M. Goodner, B. Boyes, and E. Hoy, "Detection and identification of significant ANAs in previously determined ANA negative samples," Clinical Laboratory, vol. 51, no. 9-10, pp. 517-521, 2005.

[81] X. Bossuyt, J. Frans, A. Hendrickx, G. Godefridis, R. Westhovens, and G. Mariën, "Detection of anti-SSA antibodies by indirect immunofluorescence," Clinical Chemistry, vol. 50, no. 12, pp. 2361-2369, 2004.

[82] A. Watanabe, M. Kodera, K. Sugiura et al., "Anti-DFS70 antibodies in 597 healthy hospital workers," Arthritis \& Rheumatism, vol. 50, no. 3, pp. 892-900, 2004.

[83] O. Shovman, B. Gilburd, O. Barzilai et al., "Evaluation of the BioPlex 2200 ANA screen. Analysis of 510 healthy subjects: incidence of natural/predictive autoantibodies," Annals of the New York Academy of Sciences, vol. 1050, pp. 380-388, 2005.

[84] R. A. Gniewek, D. P. Stites, T. M. McHugh, J. F. Hilton, and M. Nakagawa, "Comparison of antinuclear antibody testing methods: immunofluorescence assay versus enzyme immunoassay," Clinical and Diagnostic Laboratory Immunology, vol. 4, no. 2, pp. 185-188, 1997.

[85] E. Avaniss-Aghajani, S. Berzon, and A. Sarkissian, "Clinical value of multiplexed bead-based immunoassays for detection of autoantibodies to nuclear antigens," Clinical and Vaccine Immunology, vol. 14, no. 5, pp. 505-509, 2007.

[86] K. Sugisaki, I. Takeda, T. Kanno et al., "An anti-nuclear antibody-negative patient with systemic lupus erythematosus (SLE) accompanied with anti-ribosomal P antibody (anti-P)," Internal Medicine, vol. 41, no. 11, pp. 1047-1051, 2002.

[87] Y. Muro, K. Sugiura, Y. Morita, and Y. Tomita, "Evaluation of anti-ribosomal $\mathrm{P}$ protein immunoassay in Japanese patients with connective tissue diseases: comparison with an indirect immunofluorescence assay," Scandinavian Journal of Rheumatology, vol. 38, no. 6, pp. 460-463, 2009. 
[88] I. Peene, W. Van Ael, M. Vandenbossche, T. Vervaet, E. Veys, and F. De Keyser, "Sensitivity of the HEp-2000 substrate for the detection of anti-SSA/Ro60 antibodies," Clinical Rheumatology, vol. 19, no. 4, pp. 291-295, 2000.

[89] M. J. Fritzler, C. Hanson, J. Miller, and T. Eystathioy, "Specificity of autoantibodies to SS-A/Ro on a transfected and overexpressed human $60 \mathrm{kDa}$ Ro autoantigen substrate," Journal of Clinical Laboratory Analysis, vol. 16, no. 2, pp. 103-108, 2002.

[90] N. Tanaka, Y. Muro, K. Sugiura, and Y. Tomita, "Anti-SSA/Ro antibody determination by indirect immunofluorescence and comparison of different methods of anti-nuclear antibody screening," Modern Rheumatology, vol. 18, no. 6, pp. 585-592, 2008.

[91] S. L. Wang, F. F. Wang, S. L. Chen et al., "Expression localization and clinical application of exogenous Smith proteins D1 in gene transfected HEp-2 cells," International Journal of Rheumatic Diseases, vol. 16, pp. 303-309, 2013.

[92] C. Dahle, T. Skogh, A. K. Åberg, A. Jalal, and P. Olcén, "Methods of choice for diagnostic antinuclear antibody (ANA) screening: benefit of adding antigen-specific assays to immunofluorescence microscopy," Journal of Autoimmunity, vol. 22, no. 3, pp. 241-248, 2004.

[93] M. J. Fritzler, J. B. Rattner, L. M. Luft et al., "Historical perspectives on the discovery and elucidation of autoantibodies to centromere proteins (CENP) and the emerging importance of antibodies to CENP-F," Autoimmunity Reviews, vol. 10, no. 4, pp. 194-200, 2011.

[94] S. Khan, A. Alvi, S. Holding et al., "The clinical significance of antinucleolar antibodies," Journal of Clinical Pathology, vol. 61, no. 3, pp. 283-286, 2008.

[95] N. Bizzaro, E. Tonutti, D. Visentini et al., "Antibodies to the lens and cornea in anti-DFS70-positive subjects," Annals of the New York Academy of Sciences, vol. 1107, pp. 174-183, 2007.

[96] M. Okamoto, Y. Ogawa, A. Watanabe et al., "Autoantibodies to DFS70/LEDGF are increased in alopecia areata patients," Journal of Autoimmunity, vol. 23, no. 3, pp. 257-266, 2004.

[97] N. Kuwabara, Y. Itoh, T. Igarshi, and Y. Fukunaga, "Autoantibodies to lens epithelium-derived growth factor/transcription co-activator P75 (LEDGF/P75) in children with chronic nonspecific complaints and with positive antinuclear antibodies," Autoimmunity, vol. 42, no. 6, pp. 492-496, 2009.

[98] Y. Muro, K. Sugiura, Y. Morita, and Y. Tomita, "High concomitance of disease marker autoantibodies in anti-DFS70/LEDGF autoantibody-positive patients with autoimmune rheumatic disease," Lupus, vol. 17, no. 3, pp. 171-176, 2008.

[99] V. Ganapathy and C. A. Casiano, "Autoimmunity to the nuclear autoantigen DFS70 (LEDGF): what exactly are the autoantibodies trying to tell us?" Arthritis \& Rheumatism, vol. 50, no. 3, pp. 684-688, 2004.

[100] V. Ganapathy, T. Daniels, and C. A. Casiano, "LEDGF/p75: a novel nuclear autoantigen at the crossroads of cell survival and apoptosis," Autoimmunity Reviews, vol. 2, no. 5, pp. 290-297, 2003.

[101] M. Mahler, J. G. Hanly, and M. J. Fritzler, "Importance of the dense fine speckled pattern on HEp-2 cells and anti-DFS70 antibodies for the diagnosis of systemic autoimmune diseases," Autoimmunity Reviews, vol. 11, no. 9, pp. 642-645, 2012.

[102] M. Mahler and M. J. Fritzler, "The clinical significance of the dense fine speckled immunofluorescence pattern on HEp2 cells for the diagnosis of systemic autoimmune diseases," Clinical and Developmental Immunology, vol. 2012, Article ID 494356, 6 pages, 2012.
[103] H. A. Mariz, E. I. Sato, S. H. Barbosa, S. H. Rodrigues, A. Dellavance, and L. E. Andrade, "Ana HEp-2 pattern is a critical parameter for discriminating ana-positive healthy individuals and patients with autoimmune rheumatic diseases," Arthritis \& Rheumatology. Arthritis Rheum. 2011;63:191-200.

[104] M. J. Fritzler, "The antinuclear antibody test: last or lasting gasp?” Arthritis \& Rheumatism, vol. 63, no. 1, pp. 19-22, 2011.

[105] Y. Ogawa, K. Sugiura, A. Watanabe et al., "Autoantigenicity of DFS70 is restricted to the conformational epitope of C-terminal alpha-helical domain," Journal of Autoimmunity, vol. 23, no. 3, pp. 221-231, 2004.

[106] M. Fenger, A. Wiik, M. Høier-Madsen et al., "Detection of antinuclear antibodies by solid-phase immunoassays and immunofluorescence analysis," Clinical Chemistry, vol. 50, no. 11, pp. 2141-2147, 2004.

[107] E. Tonutti, D. Bassetti, A. Piazza et al., "Diagnostic accuracy of Elisa methods as an alternative screening test to indirect immunofluorescence for the detection of antinuclear antibodies. Evaluation of five commercial kits," Autoimmunity, vol. 37, no. 2, pp. 171-176, 2004.

[108] P. Kern, M. Kron, and K. Hiesche, "Measurement of antinuclear antibodies: assessment of different test systems," Clinical and Diagnostic Laboratory Immunology, vol. 7, no. 1, pp. 72-78, 2000.

[109] M. López-Hoyos, V. Rodríguez-Valverde, and V. MartinezTaboada, "Performance of antinuclear antibody connective tissue disease screen," Annals of the New York Academy of Sciences, vol. 1109, pp. 322-329, 2007.

[110] D. Sinclair, M. Saas, D. Williams, M. Hart, and R. Goswami, "Can an ELISA replace immunofluorescence for the detection of anti-nuclear antibodies? - the routine use of anti-nuclear antibody screening ELISAs," Clinical Laboratory, vol. 53, no. 34, pp. 183-191, 2007.

[111] J. Schmitt and W. Papisch, "Recombinant autoantigens," Autoimmunity Reviews, vol. 1, no. 1-2, pp. 79-88, 2002.

[112] J. Schulte-Pelkum, M. Fritzler, and M. Mahler, "Latest update on the Ro/SS-A autoantibody system," Autoimmunity Reviews, vol. 8, no. 7, pp. 632-637, 2009.

[113] M. Mahler, E. D. Silverman, J. Schulte-Pelkum, and M. J. Fritzler, "Anti-Scl-70 (topo-I) antibodies in SLE: myth or reality?" Autoimmunity Reviews, vol. 9, no. 11, pp. 756-760, 2010.

[114] M. Mahler, "Sm peptides in differentiation of autoimmune diseases," Advances in Clinical Chemistry, vol. 54, pp. 109-128, 2011.

[115] M. Mahler, E. D. Silverman, and M. J. Fritzler, "Novel diagnostic and clinical aspects of anti-PCNA antibodies detected by novel detection methods," Lupus, vol. 19, no. 13, pp. 1527-1533, 2010.

[116] M. Mahler, K. Miyachi, C. Peebles, and M. J. Fritzler, "The clinical significance of autoantibodies to the proliferating cell nuclear antigen (PCNA)," Autoimmunity Reviews, vol. 11, pp. 771-775, 2012.

[117] L. Maes, D. Blockmans, P. Verschueren et al., "Anti-PM/Scl100 and anti-RNA-polymerase III antibodies in scleroderma," Clinica Chimica Acta, vol. 411, no. 13-14, pp. 965-971, 2010.

[118] M. Mahler, C. Gascon, S. Patel et al., "Rpp25 is a major target of autoantibodies to the Th/To complex as measured by a novel chemiluminescent assay," Arthritis Research \& Therapy, vol. 15, article R50, 2013.

[119] C. Bordet, "Performance of the Inno-Lia Ana test in the detection of the main autoantibodies involved in connective tissue diseases," Annales de Biologie Clinique, vol. 59, no. 6, pp. 767-768, 2001. 
[120] S. A. Lee, J. Kahng, Y. Kim et al., "Comparative study of immunofluorescent antinuclear antibody test and line immunoassay detecting 15 specific autoantibodies in patients with systemic rheumatic disease," Journal of Clinical Laboratory Analysis, vol. 26, pp. 307-314, 2012.

[121] F. J. López-Longo, M. Rodríguez-Mahou, M. Escalona-Monge, C. M. González, I. Monteagudo, and L. Carreño-Pérez, "Simultaneous identification of various antinuclear antibodies using an automated multiparameter line immunoassay system," Lupus, vol. 12, no. 8, pp. 623-629, 2003.

[122] D. Almeida González, A. Cabrera de León, M. D. C. Rodríguez Pérez et al., "Efficiency of different strategies to detect autoantibodies to extractable nuclear antigens," Journal of Immunological Methods, vol. 360, no. 1-2, pp. 89-95, 2010.

[123] O. Shovman, B. Gilburd, G. Zandman-Goddard, A. Yehiely, P. Langevitz, and Y. Shoenfeld, "Multiplexed AtheNA multilyte immunoassay for ANA screening in autoimmune diseases," Autoimmunity, vol. 38, no. 1, pp. 105-109, 2005.

[124] J. G. Hanly, L. Su, V. Farewell, and M. J. Fritzler, "Comparison between multiplex assays for autoantibody detection in systemic lupus erythematosus," Journal of Immunological Methods, vol. 358, no. 1-2, pp. 75-80, 2010.

[125] J. G. Hanly, K. Thompson, G. McCurdy, L. Fougere, C. Theriault, and K. Wilton, "Measurement of autoantibodies using multiplex methodology in patients with systemic lupus erythematosus," Journal of Immunological Methods, vol. 352, no. 1-2, pp. 147$152,2010$.

[126] P. Caramaschi, O. Ruzzenente, S. Pieropan et al., "Determination of ANA specificity using multiplexed fluorescent microsphere immunoassay in patients with ANA positivity at high titres after infliximab treatment: preliminary results," Rheumatology International, vol. 27, no. 7, pp. 649-654, 2007.

[127] S. S. Copple, T. B. Martins, C. Masterson, E. Joly, and H. R. Hill, "Comparison of three multiplex immunoassays for detection of antibodies to extractable nuclear antibodies using clinically defined sera," Annals of the New York Academy of Sciences, vol. 1109, pp. 464-472, 2007.

[128] B. Gilburd, M. Abu-Shakra, Y. Shoenfeld et al., "Autoantibodies profile in the sera of patients with sjogren's syndrome: the ANA evaluation-a homogeneous, multiplexed system," Clinical and Developmental Immunology, vol. 11, no. 1, pp. 53-56, 2004.

[129] A.-P. Nifli, G. Notas, M. Mamoulaki et al., "Comparison of a multiplex, bead-based fluorescent assay and immunofluorescence methods for the detection of ANA and ANCA autoantibodies in human serum," Journal of Immunological Methods, vol. 311, no. 1-2, pp. 189-197, 2006.

[130] K. Uto, N. Hayashi, S. Kinoshita, S. Kawano, and S. Kumagai, "Evaluation of simultaneous detection of specific antinuclear antibodies using multiplexed technology," Rinsho Byori, vol. 57, no. 10, pp. 941-953, 2009.

[131] M. J. Fritzler, F. Behmanesh, and M. L. Fritzler, "Analysis of human sera that are polyreactive in an addressable laser bead immunoassay," Clinical Immunology, vol. 120, no. 3, pp. 349356, 2006.

[132] S. Bernardini, M. Infantino, L. Bellincampi et al., "Screening of antinuclear antibodies: comparison between enzyme immunoassay based on nuclear homogenates, purified or recombinant antigens and immunofluorescence assay," Clinical Chemistry and Laboratory Medicine, vol. 42, no. 10, pp. 11551160, 2004.

[133] P. M. Bayer, S. Bauerfeind, J. Bienvenu et al., "Multicenter evaluation study on a new HEP2 ANA screening enzyme immune assay," Journal of Autoimmunity, vol. 13, no. 1, pp. 8993, 1999.

[134] P. M. Bayer, B. Fabian, and W. Hübl, "Immunofluorescence assays (IFA) and enzyme-linked immunosorbent assays (ELISA) in autoimmune disease diagnostics - technique, benefits, limitations and applications," Scandinavian Journal of Clinical and Laboratory Investigation, Supplement, vol. 61, no. 235, pp. 68-76, 2001.

[135] H.-P. Lehmann, D. Block, C. Markert-Hahn, and J. W. Zolg, "New concepts in systemic autoimmunity testing," Scandinavian Journal of Clinical and Laboratory Investigation, Supplement, vol. 61, no. 235, pp. 84-90, 2001.

[136] H.-P. Lehmann, I. Fuhling, C. Ott, B. Hudepohl, and M. Haass, "HEp2 ANA EIA: a new fully automated assay for the screening of antinuclear antibodies," Israel Medical Association Journal, vol. 2, no. 8, pp. 646-648, 2000.

[137] X. Bossuyt, "Evaluation of two automated enzyme immunoassays for detection of antinuclear antibodies," Clinical Chemistry and Laboratory Medicine, vol. 38, no. 10, pp. 1033-1037, 2000.

[138] N. Hayashi, T. Kawamoto, M. Mukai et al., "Detection of antinuclear antibodies by use of an enzyme immunoassay with nuclear HEp-2 cell extract and recombinant antigens: comparison with immunofluorescence assay in 307 patients," Clinical Chemistry, vol. 47, no. 9, pp. 1649-1659, 2001.

[139] G. A. Maguire, A. Ginawi, J. Lee et al., "Clinical utility of ANA measured by ELISA compared with ANA measured by immunofluorescence," Rheumatology, vol. 48, no. 8, pp. 10131014, 2009.

[140] P. Ghillani, A. M. Rouquette, C. Desgruelles et al., "Evaluation of the LIAISON ANA screen assay for antinuclear antibody testing in autoimmune diseases," Annals of the New York Academy of Sciences, vol. 1109, pp. 407-413, 2007.

[141] L. K. Peterson, D. Wells, L. Shaw, M.-G. Velez, R. Harbeck, and L. L. Dragone, "Novel method for quantitative ANA measurement using near-infrared imaging," Journal of Immunological Methods, vol. 349, no. 1-2, pp. 1-8, 2009.

[142] K. Grossmann, D. Roggenbuck, C. Schröder, K. Conrad, P. Schierack, and U. Sack, "Multiplex assessment of nonorgan-specific autoantibodies with a novel microbead-based immunoassay," Cytometry A, vol. 79, no. 2, pp. 118-125, 2011.

[143] J. Smith, D. Onley, C. Garey et al., "Determination of ANA specificity using the UltraPlexÜ platform," Annals of the New York Academy of Sciences, vol. 1050, pp. 286-294, 2005.

[144] W. H. Robinson, C. DiGennaro, W. Hueber et al., "Autoantigen microarrays for multiplex characterization of autoantibody responses," Nature Medicine, vol. 8, no. 3, pp. 295-301, 2002.

[145] P. J. Utz, "Multiplexed assays for identification of biomarkers and surrogate markers in systemic lupus erythematosus," Lupus, vol. 13, no. 5, pp. 304-311, 2004.

[146] I. Balboni, C. Limb, J. D. Tenenbaum, and P. J. Utz, "Evaluation of microarray surfaces and arraying parameters for autoantibody profiling," Proteomics, vol. 8, no. 17, pp. 3443-3449, 2008.

[147] C. González, B. García-Berrocal, M. Pérez, J. A. Navajo, O. Herraez, and J. M. González-Buitrago, "Laboratory screening of connective tissue diseases by a new automated ENA screening assay (EliA Symphony) in clinically defined patients," Clinica Chimica Acta, vol. 359, no. 1-2, pp. 109-114, 2005.

[148] J. C. Parker and C. C. Bunn, "Sensitivity of the Phadia EliA connective tissue disease screen for less common diseasespecific autoantibodies," Journal of Clinical Pathology, vol. 64, no. 7, pp. 631-633, 2011. 
[149] C. Bentow, A. Seaman, A. Swart, A. Shikhman, N. Goodman, and M. and Mahler, "Evaluation of a novel chemiluminescent assay (QUANTA Flash CTD Screen Plus) for the rapid detection of autoantibodies in systemic autoimmune rheumatic diseases," in Proceedings of the 11th Dresden Symposium on Autoantibodies, Dresden, Germany, 2013.

[150] E. K. L. Chan, M. J. Fritzler, A. Wiik et al., "AutoAbSC.Orgautoantibody standardization committee in 2006," Autoimmunity Reviews, vol. 6, no. 8, pp. 577-580, 2007.

[151] X. Bossuyt, C. Louche, and A. Wiik, "Standardisation in clinical laboratory medicine: an ethical reflection," Annals of the Rheumatic Diseases, vol. 67, no. 8, pp. 1061-1063, 2008.

[152] M. J. Fritzler, A. Wiik, E. M. Tan et al., "A critical evaluation of enzyme immunoassay kits for detection of antinuclear autoantibodies of defined specificities. III. Comparative performance characteristics of academic and manufacturers' laboratories," Journal of Rheumatology, vol. 30, no. 11, pp. 2374-2381, 2003.

[153] J. S. Smolen, B. Butcher, M. J. Fritzler et al., "Reference sera for antinuclear antibodies: II. Further definition of antibody specificities in international antinuclear antibody reference sera by immunofluorescence and western blotting," Arthritis \& Rheumatism, vol. 40, no. 3, pp. 413-418, 1997.

[154] E. M. Tan, J. S. Smolen, J. S. McDougal et al., "A critical evaluation of enzyme immunoassays for detection of antinuclear autoantibodies of defined specificities. I. Precision, sensitivity, and specificity," Arthritis \& Rheumatology, vol. 42, pp. 455-464, 1999.

[155] E. M. Tan, J. S. Smolen, J. S. McDougal et al., "A critical evaluation of enzyme immunoassay kits for detection of antinuclear autoantibodies of defined specificities. II. Potential for quantitation of antibody content," Journal of Rheumatology, vol. 29, no. 1, pp. 68-74, 2002.

[156] K. James, A. B. Carpenter, L. Cook, R. Marchand, and R. M. Nakamura, "Development of the antinuclear and anticytoplasmic antibody consensus panel by the Association of Medical Laboratory Immunologists," Clinical and Diagnostic Laboratory Immunology, vol. 7, no. 3, pp. 436-443, 2000.

[157] M. Mahler, M. J. Fritzler, and M. Blüthner, "Identification of a SmD3 epitope with a single symmetrical dimethylation of an arginine residue as a specific target of a subpopulation of antiSm antibodies," Arthritis Research \& Therapy, vol. 7, no. 1, pp. R19-R29, 2005.

[158] T. E. W. Feltkamp, "Standards for ANA and anti-DNA," Clinical Rheumatology, vol. 9, no. 1, pp. 74-81, 1990.

[159] J. Damoiseaux, J. W. C. Tervaert, R. Derksen et al., "Autoantibody standardization in the Netherlands: the past, the present, and the future," Annals of the New York Academy of Sciences, vol. 1173, pp. 10-14, 2009.

[160] U. Sack, K. Conrad, E. Csernok et al., "Standardization of autoimmune diagnostics in Germany: activities of the German group in the European autoimmune standardization initiative," Annals of the New York Academy of Sciences, vol. 1109, pp. 31-36, 2007.

[161] P. L. Meroni, M. Biggioggero, S. S. Pierangeli, J. Sheldon, I. Zegers, and M. O. Borghi, "Standardization of autoantibody testing: a paradigm for serology in rheumatic diseases," Nature Reviews Rheumatology, vol. 10, pp. 35-43, 2014. 


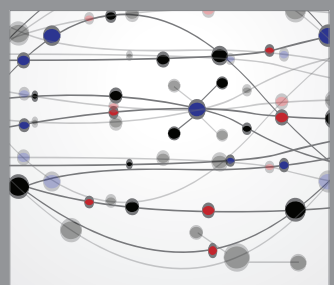

The Scientific World Journal
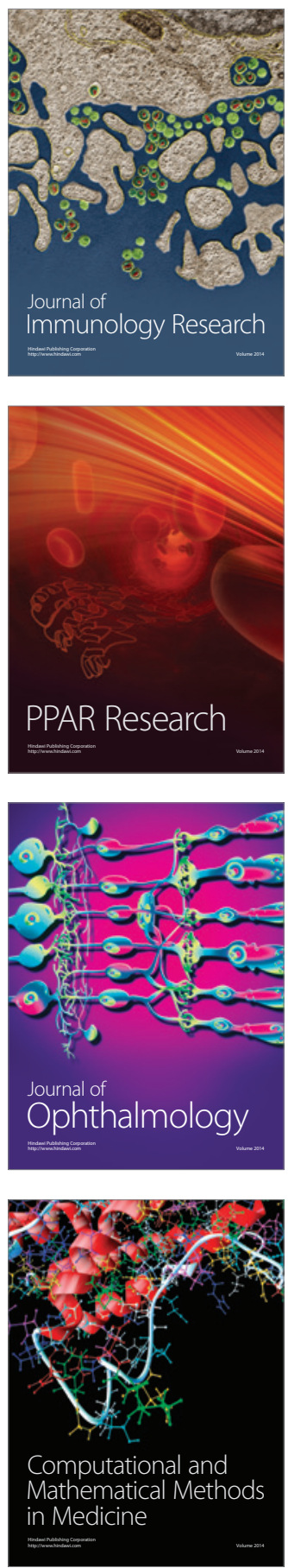

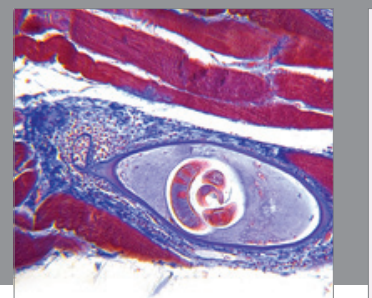

Gastroenterology

Research and Practice
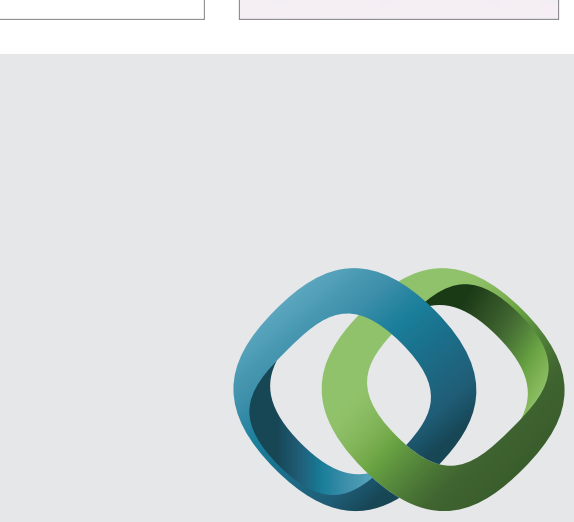

\section{Hindawi}

Submit your manuscripts at

http://www.hindawi.com
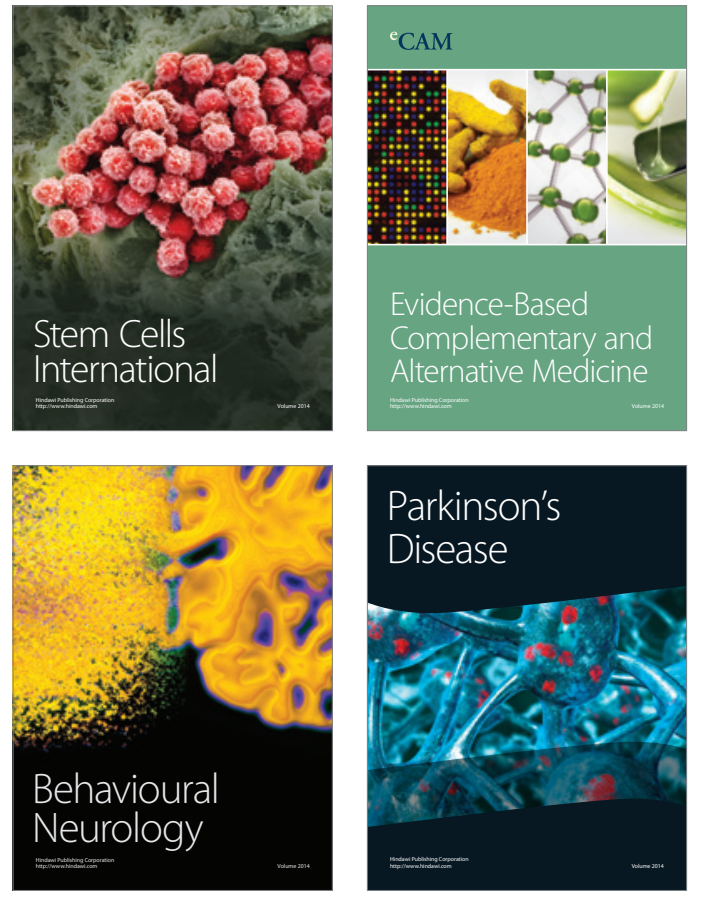
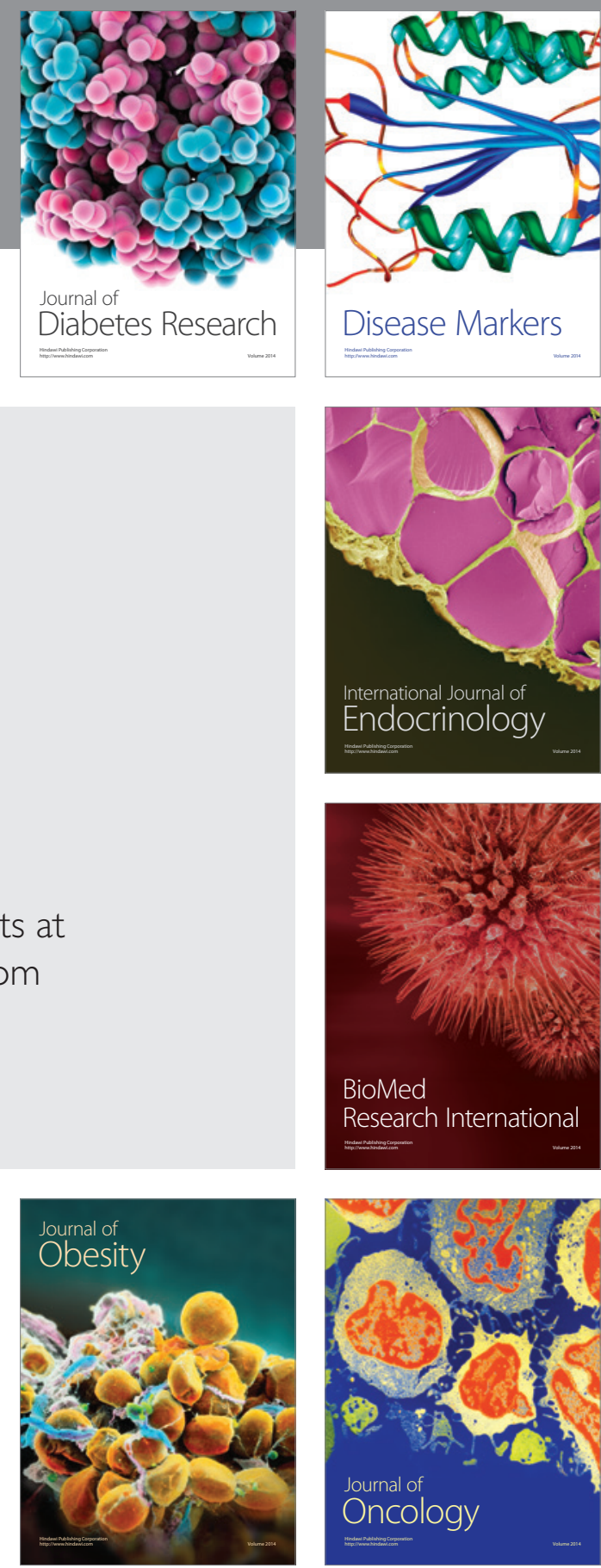

Disease Markers
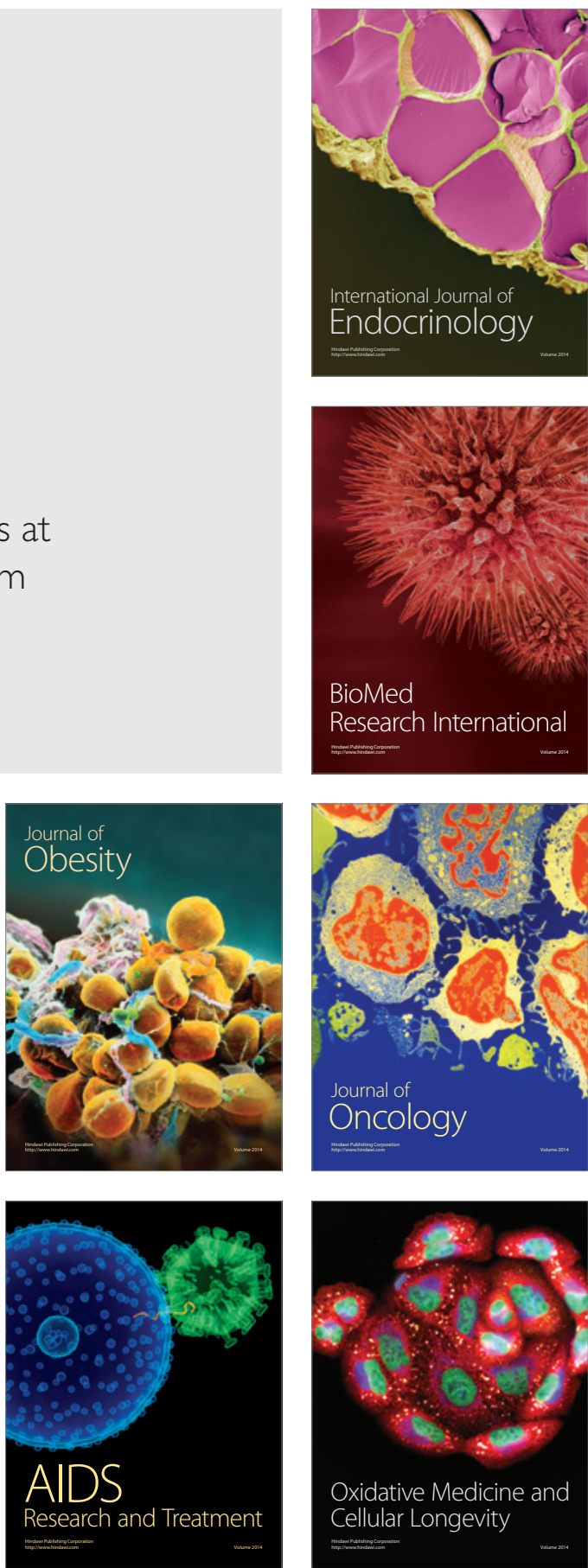